\title{
Modeling and Design Optimization of Multifunctional Membrane Reactors for Direct Methane Aromatization
}

Nicholas J. Fouty

Follow this and additional works at: https://researchrepository.wvu.edu/etd

\section{Recommended Citation}

Fouty, Nicholas J., "Modeling and Design Optimization of Multifunctional Membrane Reactors for Direct Methane Aromatization" (2017). Graduate Theses, Dissertations, and Problem Reports. 5615.

https://researchrepository.wvu.edu/etd/5615

This Thesis is protected by copyright and/or related rights. It has been brought to you by the The Research Repository @ WVU with permission from the rights-holder(s). You are free to use this Thesis in any way that is permitted by the copyright and related rights legislation that applies to your use. For other uses you must obtain permission from the rights-holder(s) directly, unless additional rights are indicated by a Creative Commons license in the record and/ or on the work itself. This Thesis has been accepted for inclusion in WVU Graduate Theses, Dissertations, and Problem Reports collection by an authorized administrator of The Research Repository @ WVU. For more information, please contact researchrepository@mail.wvu.edu. 


\title{
Modeling and Design Optimization of Multifunctional Membrane Reactors for Direct Methane Aromatization
}

\author{
Nicholas J. Fouty \\ Thesis submitted to the \\ Benjamin M. Statler College of Engineering and Mineral Resources \\ at West Virginia University
}

In partial fulfillment of the requirements for the degree of

Master of Science in

Chemical Engineering

\author{
Fernando V. Lima, Ph.D., Chair \\ Debangsu Bhattacharyya, Ph.D. \\ Jeevan Maddala, Ph.D.
}

Department of Chemical and Biomedical Engineering

Morgantown, West Virginia

2017

Keywords: optimization, multifunctional membrane reactors, direct methane aromatization, natural gas utilization, modeling, design 


\title{
Abstract \\ Modeling and Design Optimization of Multifunctional Membrane Reactors for Direct Methane Aromatization
}

\author{
Nicholas J. Fouty
}

\begin{abstract}
Due to the recent increase of natural gas production in the U.S., utilizing natural gas for higher-value chemicals has become imperative. Direct methane aromatization (DMA) is a promising process used to convert methane to benzene, but it is limited by low conversion of methane and rapid catalyst deactivation by coking. Past work has shown that membrane separation of the hydrogen produced in the DMA reactions can dramatically increase the methane conversion by shifting the equilibrium toward the products, but it also increases coke production. Oxygen introduction into the system has been shown to inhibit this coke production while not inhibiting the benzene production. This thesis introduces a novel mathematical model and design to employ both methods in a multifunctional membrane reactor to push the DMA process into further viability. Multifunctional membrane reactors, in this case, are reactors where two different separations occur using two differently selective membranes, on which no systems studies have been found. The proposed multifunctional membrane design incorporates a hydrogen-selective membrane on the outer wall of the reaction zone, and an inner tube filled with air flow surrounded by an oxygen-selective membrane in the middle of the reactor. The design is shown to increase conversion via hydrogen removal by around $100 \%$, and decrease coke production via oxygen addition by $10 \%$ when compared to a tubular reactor without any membranes. Optimization studies are performed to determine the best reactor design based on methane conversion, along with coke and benzene production. The obtained optimal design considers a small reactor (length $=25 \mathrm{~cm}$, diameter of reaction tube $=0.7 \mathrm{~cm}$ ) to subvert coke production and consumption of the product benzene as well as a high permeance $\left(0.01 \mathrm{~mol} / \mathrm{s} \cdot \mathrm{m}^{2} \cdot \mathrm{atm}^{1 / 4}\right)$ through the hydrogen-permeable membrane. An independent optimal design of the oxygen permeable membrane calls for low oxygen flux (permeance $=2.09 \mathrm{~mol} / \mathrm{s} \mathrm{m}^{2} . \mathrm{atm}^{1 / 4}$, diameter of air tube $=0.5 \mathrm{~cm}$ ) so oxidative reactions do not inhibit benzene production. This modeling and design approach sets the stage for guiding further development of multifunctional membrane reactor models and designs for natural gas utilization and other chemical reaction systems.
\end{abstract}




\section{Dedicated to my parents John and Toni, my sister Erin, my niece Jada, and my nephew Jaxon}




\section{Acknowledgements}

I would like to thank everyone who made my six years of undergraduate and graduate studies at West Virginia University a fantastic experience that I will never forget.

First, I thank Dr. Fernando V. Lima for the opportunity to extend my education to graduate studies in his CODES research group. His seemingly never-ending patience and support as my research advisor helped to guide my development as a student and researcher. I extend my deepest gratitude to him, Dr. Debangsu Bhattacharyya, and Dr. Robin Hissam for fighting for Matt and me to have our Graduate Teaching Assistantships. I also thank Dr. Lima, Dr. Bhattacharyya, and Dr. Jeevan Maddala for forming my M.S. committee and giving me new perspectives to learn from. I would also like to thank Dr. Richard Turton, with Dr. Lima and Dr. Bhattacharyya, for teaching me chemical process design and inspiring me to study design. The knowledge and experience I gained in Senior Design will forever stay with me as I learned to take the tough questions and argue for my own work. I would also like to thank Dr. Dongxia Liu (UMD) and her group for initial DMA conditions and assistance. I am also eternally grateful to Dr. Juan C. Carrasco for his teaching, support, and unforgettable kindness. I also thank all the wonderful professors that I had throughout higher education at WVU.

I extend my gratitude to all of my friends from Charleston and WVU for all the good times: Nick B., Justin, Isaac, Jacob, Jeff, Michael, Cameron, Ayman, Richard, Rodberg, Scohy, Montana, Benton, Panger, Catherine, Joy, Kelley, Chris, Joe M., Greg, Tanner, JP, Steve, Derek, Kevin, Dr. Jeremy Hardinger, Tony, Jake, Brent, Andrew W., Andrew G., Alix, Bryce, John, Zach, Joe C., Marsha, Alex, Kara, Dave, and James. I also thank all of the CODES group for their support.

Finally and most importantly, I thank my love Kim for supporting me and being the best friend anyone could ask for, my parents John and Toni for embedding the importance of education in me and their constant coaching and support in my life, and my sister Erin for being an example I could always look to. 


\section{Table of Contents}

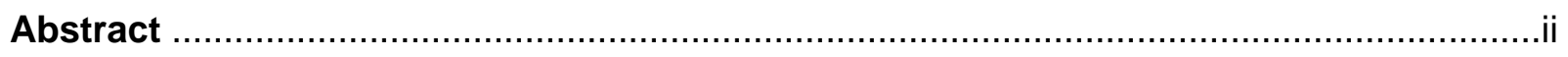

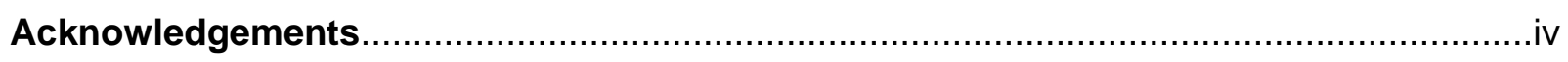

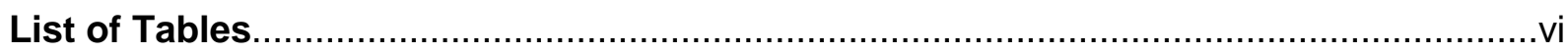

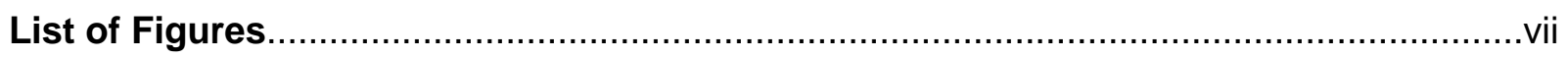

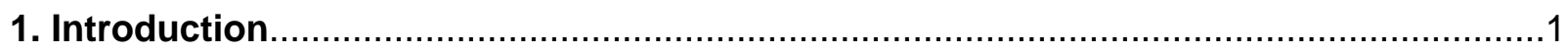

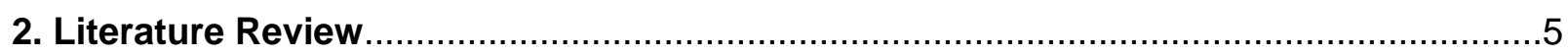

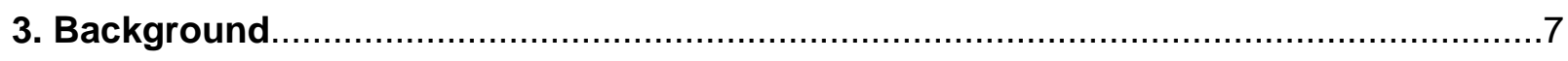

3.1 DMA Membrane Reactor Model..........................................................

3.2 Role of Selective Oxidation.................................................................

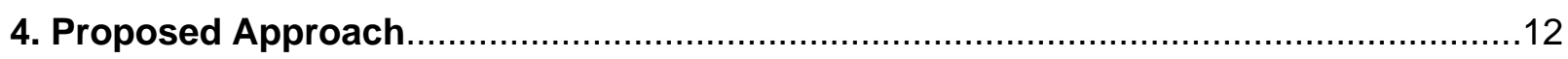

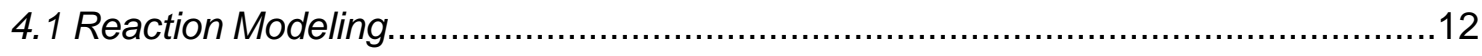

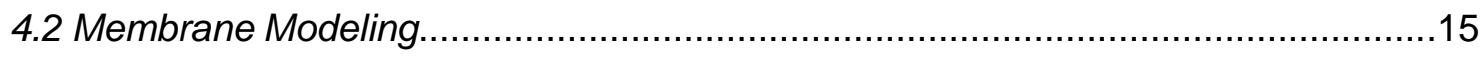

4.3 Simulation and Optimization Setup.................................................... 18

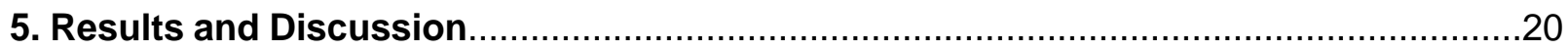

5.1 Base Case Performance Studies...............................................................20

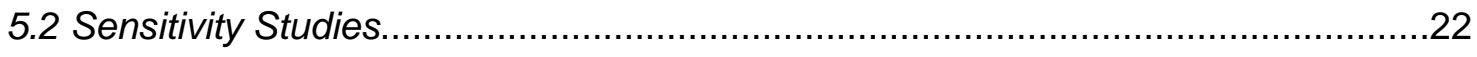

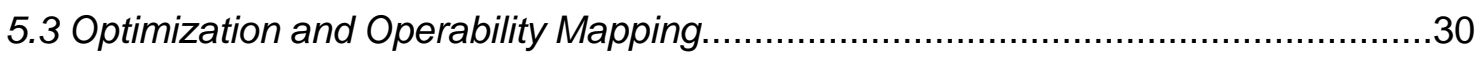

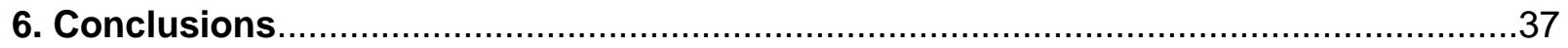

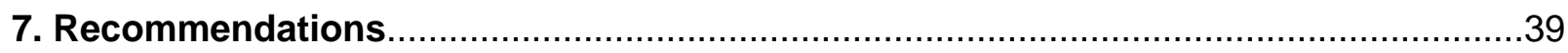

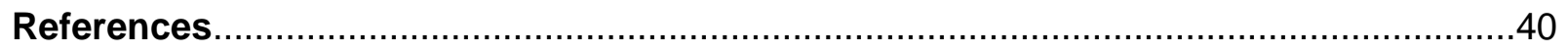




\section{List of Tables}

Table 1. Kinetic model parameters for DMA, OCM, and pyrolysis reactions mechanisms......15

Table 2. Base case simulation design and process conditions......................................19

Table 3. Base case performance criteria results: Base uses no membrane, $\mathrm{M} 1$ uses $\mathrm{H}_{2}-$ permeable membrane, $\mathrm{M} 2$ uses $\mathrm{O}_{2}$-permeable membrane, and Multifunctional uses

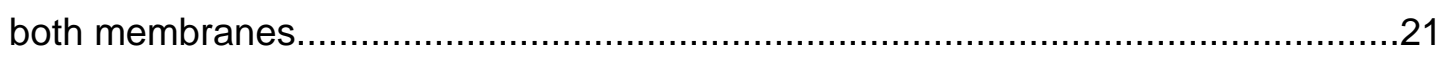

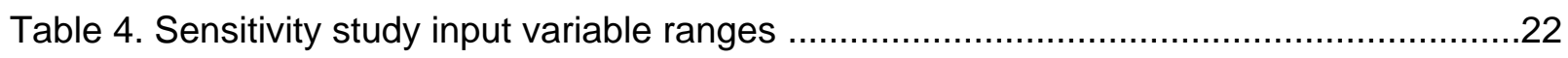

Table 5. Optimal reactor designs and outputs with modified objective functions: Case 1 has equally weighted criteria, as seen in $\boldsymbol{\varphi}$; Case 2 has 100 times weight on $\mathrm{F}_{\mathrm{C} 6 \mathrm{H} 6}$; Case 3 has 100 times weight on $\mathrm{X}_{\mathrm{CH} 4}$; Case 4 has 100 times weight on $\mathrm{C}_{\mathrm{C} . \ldots \ldots \ldots \ldots \ldots \ldots . . . . . . . . . . .37}$ 


\section{List of Figures}

Figure 1: Equilibrium conversion of methane for direct conversion methods under non-

oxidative conditions [37].

Figure 2: Benzene formation in typical DMA processes (I. Activation. II. Pseudo-steady state.

III. Deactivation) [9].

Figure 3: Membrane reactor co-current configuration [5]. 8

Figure 4: Methane conversion over time for membrane reactor (MR) and fixed-bed reactor

(FR) (left). Product selectivity (right) [2].

Figure 5. Multifunctional membrane reactor design for DMA.

Figure 6. Sensitivity studies of $\mathbf{Q}_{\mathbf{2}}$ for model performance criteria: $\mathrm{X}_{\mathrm{CH} 4}$ (top), $\mathrm{C}_{\mathrm{C}}$ (middle), $\mathrm{F}_{\mathrm{C} 6 \mathrm{H} 6}$ (bottom) .23

Figure 7. Case 1 study of $\mathbf{d}_{2}$ for model performance criteria: $\mathrm{X}_{\mathrm{CH} 4}$ (top), $\mathrm{C}_{\mathrm{C}}$ (middle), $\mathrm{F}_{\mathrm{C} 6 \mathrm{H} 6}$

(bottom) 25

Figure 8. Case 2 study of $\mathbf{d}_{2}$ for model performance criteria: $\mathrm{X}_{\mathrm{CH} 4}$ (top), $\mathrm{C}_{\mathrm{C}}$ (middle), $\mathrm{F}_{\mathrm{C} 6 \mathrm{H} 6}$ (bottom) 25

Figure 9. Case 3 study of $\mathbf{d}_{2}$ for model performance criteria: $\mathrm{X}_{\mathrm{CH} 4}$ (top), $\mathrm{C}_{\mathrm{C}}$ (middle), $\mathrm{F}_{\mathrm{C} 6 \mathrm{H} 6}$ (bottom) .26

Figure 10 . Sensitivity studies of $\mathbf{L}$ for model performance criteria: $\mathrm{X}_{\mathrm{CH} 4}$ (top), $\mathrm{C}_{\mathrm{C}}$ (middle), $\mathrm{F}_{\mathrm{C} 6 \mathrm{H} 6}$ (bottom).

Figure 11. Sensitivity studies of $\mathbf{d}_{1}$ for model performance criteria: $\mathrm{X}_{\mathrm{CH} 4}$ (top), $\mathrm{C}_{\mathrm{C}}$ (middle),

$\mathrm{F}_{\mathrm{C} 6 \mathrm{H} 6}$ (bottom)

Figure 12 . Sensitivity studies of $\mathbf{Q}_{\mathbf{1}}$ for model performance criteria: $\mathrm{X}_{\mathrm{CH} 4}$ (top), $\mathrm{C}_{\mathrm{C}}$ (middle),

$\mathrm{F}_{\mathrm{C} 6 \mathrm{H} 6}$ (bottom)

Figure 13. Sensitivity studies of $\boldsymbol{\alpha}_{\mathrm{i}, 1}$ for model performance criteria: $\mathrm{X}_{\mathrm{CH} 4}$ (top), $\mathrm{C}_{\mathrm{C}}$ (middle),

$\mathrm{F}_{\mathrm{C} 6 \mathrm{H} 6}$ (bottom). 
Figure 14. AIS - reactor dimensions (left), AOS - $\mathrm{C}_{\mathrm{C}}$ and $\mathrm{F}_{\mathrm{C} 6 \mathrm{H} 6}$ (right) ............................32

Figure 15. AIS - M1 permeance and selectivity to hydrogen (left), AOS - $\mathrm{C}_{\mathrm{c}}$ and $\mathrm{F}_{\mathrm{C} 6 \mathrm{H} 6}$

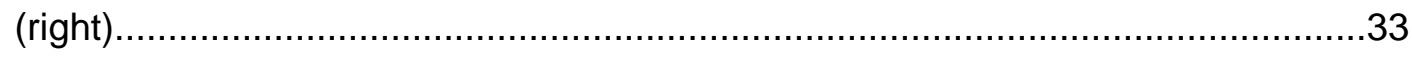

Figure 16. AIS - Permeance and diameter for $\mathrm{M} 2$ (left), AOS - $\mathrm{C}_{\mathrm{C}}$ and $\mathrm{F}_{\mathrm{C} 6 \mathrm{H} 6}$ (right).............35

Figure 17. AIS - reactor dimensions and M1 permeance (left), AOS - performance criteria

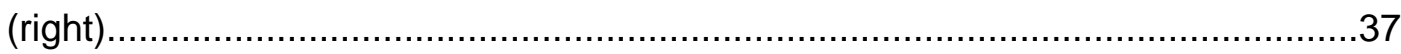




\section{Introduction}

Large reserves of natural gas have been discovered in recent years, bringing attention to their use for hydrocarbon synthesis. According to the U.S. EIA [30], 26.4 trillion cubic feet of gas was produced in 2016. Estimates expect that number only to grow in the coming years as new technologies for retrieving natural gas continue to thrive and grow themselves. By 2019, it is expected that the U.S. will produce 28 trillion cubic feet per year, with 40 percent of that coming from the Marcellus shale, which includes West Virginia and much of Appalachia [31].

Utilizing the potential of natural gas comes with the intriguing issue of converting its primary hydrocarbon, methane, to higher-value chemicals. There are different methods for performing this conversion, both direct and indirect. Indirect methods usually involve the production of synthesis gas via steam reforming or other reforming methods followed by a Fischer-Tropsch process or similar process that converts the syngas to higher-order hydrocarbons. There are several direct methods, as well $[19,25]$. These methods have been of interest in recent years due to the elimination of the syngas step, as it can be a costly process. Methods such as oxidative coupling of methane (OCM) and aromatization have begun to receive greater attention. These processes are slow to occur because conversion of methane to higher hydrocarbons is thermodynamically unfavorable and often requires temperatures in excess of $1500 \mathrm{~K}$ to achieve a viable conversion level. Now, with advances made in catalysis and the large quantity of natural gas resources available, the direct methods have potential to become feasible.

Aromatization of methane, or direct methane aromatization (DMA), in particular, has shown great potential, as it is thermodynamically more favorable to convert 
methane to aromatics directly, as opposed to olefins, as shown in Figure 1, where the equilibrium conversion to aromatics is higher than the conversion to olefins at high temperatures. When oxygen is added to a methane aromatization system, it makes the reaction of methane to benzene and hydrogen more thermodynamically favorable; however, the combustion reaction is, unfortunately, more favorable than the desired reaction, resulting in low conversions and selectivity to benzene. Wang et al. [32] first reported the non-oxidative aromatization in a fixed bed reactor using the HZSM-5 zeolite supported molybdenum catalyst (Mo/HZSM-5). For this reaction, benzene and hydrogen were produced using a pure methane feed at a high rate with minimal side products without oxygen and without combustion products. This has attracted much attention, as not only is this reaction more favorable than previous methane conversion processes, it is also environmentally conscious due to the lack of production of troublesome greenhouse gases, such as $\mathrm{CO}_{2}$. However, some issues with this method are the overall low conversion of methane and the rapid catalyst deactivation by coking. A general benzene production trend for the DMA process is shown over time in Figure 2 to highlight some of these issues. There have been many attempts to mitigate these issues, with solutions involving membranes, catalysis, and selective oxidation. 


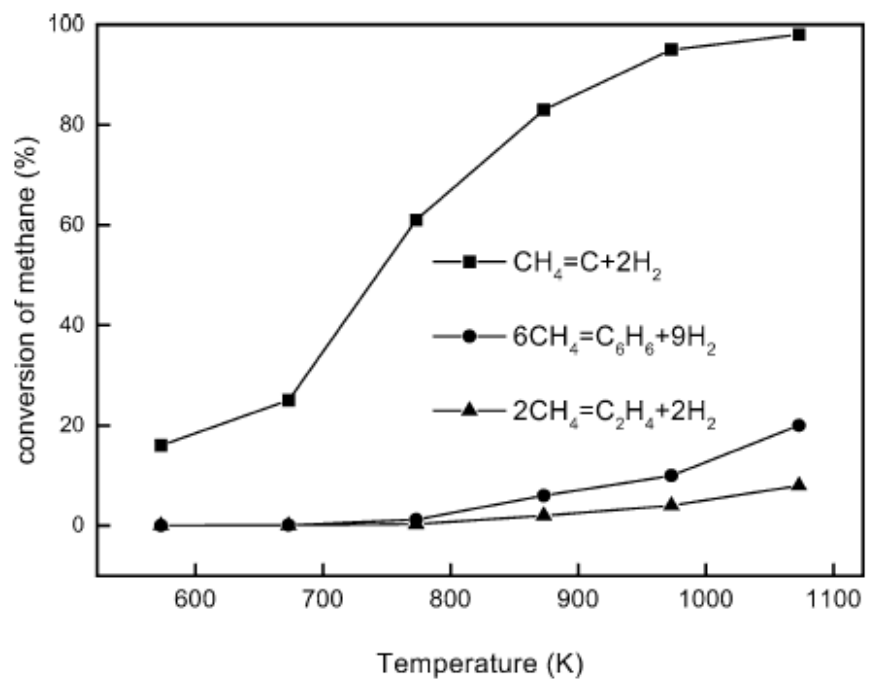

Figure 1: Equilibrium conversion of methane for direct conversion methods under non-oxidative conditions [37].

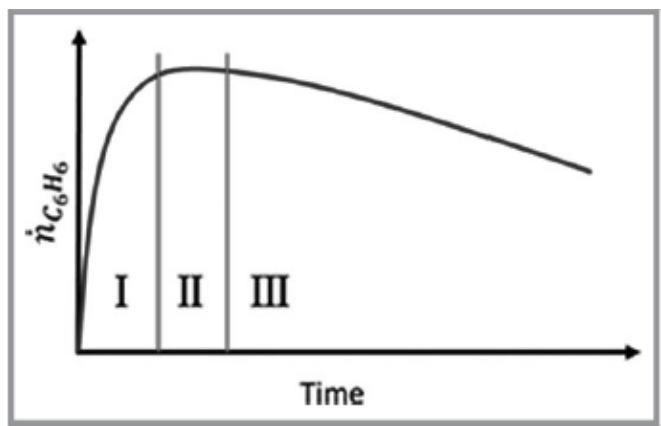

Figure 2: Benzene formation in typical DMA processes (I. Activation. II. Pseudo-steady state. III. Deactivation) [9].

Considering the information presented above, the goal of this thesis is to develop a detailed and comprehensive process model of the DMA reaction system while attempting to subvert the limitations presented above through membrane technology with design and process optimizations. Specifically, the objectives of this thesis are to:

- Objective \#1: Establish thermodynamically-based isothermal DMA reaction model with the addition of naphthalene formation.

- Objective \#2: Expand reaction scheme allowing for both non-oxidative and oxidative DMA to occur with coking. 
- Objective \#3: Develop a multi-functional comprehensive membrane reactor model allowing for the addition of oxygen to the system via membrane.

- Objective \#4: Apply model to process optimization studies allowing for the highest conversion of methane with the highest selectivity to benzene while minimizing the effects of coking.

The main results of this thesis correspond to: (i) development of a detailed and comprehensive DMA model that incorporates coking and oxidative reactions and (ii) formulation and optimization of a multifunctional membrane reactor design for this DMA model.

The contributions of this thesis have resulted in the following submitted journal paper:

- Fouty, N. J., Carrasco, J. C., and Lima, F. V. "Modeling and Design Optimization of Multifunctional Membrane Reactors for Direct Methane Aromatization". Submitted for publication in the special issue of Membranes: Membrane Transport Modeling.

The outline for the remaining sections of this thesis includes a review of literature to expose the gaps in DMA research. The basis for the membrane reactor model and the motivation for adding an oxygen-selective membrane to the system are described in the background. Next, the proposed modeling and design optimization approaches are detailed. Base-case results and sensitivity studies are then completed to validate the logic behind the designs. Finally, additional results are presented and discussed through multiple input-output mapping studies and the optimal designs are determined, followed by conclusions and recommendations for the future of the project. 


\section{Literature Review}

Non-oxidative DMA has emerged as a potential path for efficient natural gas utilization. However, the DMA process is limited by thermodynamic and kinetic constraints $[9,10,12,32]$. The overall process is endothermic and involves upgrading methane to hydrocarbons, thus leading to unrestricted carbon chain growth. All of these factors lead to low methane conversion, low benzene selectivity, and quick deactivation of the catalyst by coking. Ways to improve the process through addition of extra reactions have been reported. Addition of co-reacting alkenes and higher alkanes have been found to lower the required reaction temperature, and increase methane conversion and aromatic selectivity $[1,6]$. It has been reported that injection of $\mathrm{CO}, \mathrm{CO}_{2}$, or water suppresses coke formation through the use of steam reforming $[18,33]$. Also, oxidative coupling of methane by way of small additions of oxygen to the reactor have produced greater catalyst stability with an integrated recycle system [23]. However, none of the reported research has shown the reaction mechanisms, due to the complex nature of DMA.

There is also an abundance of research attempting to find improved catalysts and characterize their mechanisms with DMA. Though Mo-based catalysts on zeolite supports are typically used, other transition metals have been attempted, sometimes added as promoters to molybdenum or sometimes the transition metals alone, with rhenium $(R e)$ and tungsten (W) being the most successful alternatives [34,40]. HZSM5 was the original and most successful of the zeolite supports, with newer cases using the MWW or MFI supports due to favorable pore size and structure $[17,32,35,36]$. Mobased catalysts react to form molybdenum carbide, which is essential in the formation of aromatics from methane. Attempts to characterize the mechanisms for coking 
concluded that molybdenum carbide seals the channels in the zeolite support, blocking the species from reaching Bransted acid sites (BAS) [13,27-29].

Membrane reactors have emerged as a potential solution to these reaction challenges. There have been many efforts involving hydrogen-selective membranes used to overcome the equilibrium barriers, leading to higher methane conversions $[15,21,24]$. However, it has been proven difficult to replicate predictive models in experimental work due to the lack of sufficient hydrogen permeation fluxes through the membrane and of sufficient catalyst resistances to coking, which has been accelerated due to hydrogen removal $[11,24]$. It has also been shown that oxygen can be used to inhibit coke formation and to decrease catalyst deactivation by using selective oxidation [39]. By way of an oxygen permeable membrane, oxygen has been shown to decrease catalyst deactivation, though as there was no hydrogen removal in the reported study, methane conversion stayed low [2]. Oxygen pulsing has also been used to combust coke deposits in the reactor in a deactivation/regeneration cycle leading to a longer lasting catalyst [14]. Furthermore, fluidized beds have been reported to show better yields than fixed beds, due to homogeneous temperatures and easier catalyst regeneration [7].

Therefore, based on the reported studies, there is a lack of systems studies that focus on mitigating both the catalyst deactivation and the equilibrium limitations. Also, there are not many detailed studies attempting to model the oxidative DMA reaction mechanism or the coking mechanism. This thesis corresponds to a contribution aiming to fill these identified gaps. 


\section{Background}

\subsection{DMA Membrane Reactor Model}

The main contributions for the DMA membrane reactor modeling have been detailed in Carrasco and Lima [3-5], Li et al. [15,16], and Rival et al. [24]. Those contributions have been summarized below and have been essential to the beginning of this research.

DMA is the reaction of methane $\left(\mathrm{CH}_{4}\right)$ to hydrogen $\left(\mathrm{H}_{2}\right)$ and benzene $\left(\mathrm{C}_{6} \mathrm{H}_{6}\right)$. It is typically done over a molybdenum (Mo) catalyst on some zeolite support (typically HZSM-5, MWW, or MFI). Equations 1-4 represent a two-step reaction mechanism, followed by the respective rate laws,

R1:

$$
2 \mathrm{CH}_{4}=\mathrm{C}_{2} \mathrm{H}_{4}+2 \mathrm{H}_{2}
$$

R2:

$$
\begin{array}{r}
3 \mathrm{C}_{2} \mathrm{H}_{4}=\mathrm{C}_{6} \mathrm{H}_{6}+3 \mathrm{H}_{2} \\
\mathbf{r}_{1}=\mathbf{k}_{1} \mathrm{C}_{\mathrm{CH}_{4}}\left(1-\frac{\mathrm{C}_{\mathrm{C}_{2} \mathrm{H}_{4}} \mathrm{C}_{\mathrm{H}_{2}}^{2}}{\mathrm{~K}_{1} \mathrm{C}_{\mathrm{CH}_{4}}^{2}}\right) \\
\mathbf{r}_{2}=\mathbf{k}_{2} \mathrm{C}_{\mathrm{C}_{2} \mathrm{H}_{4}}\left(1-\frac{\mathrm{C}_{\mathrm{C}_{6} \mathrm{H}_{6}} \mathrm{C}_{\mathrm{H}_{2}}^{3}}{\mathrm{~K}_{2} \mathrm{C}_{\mathrm{C}_{2} \mathrm{H}_{4}}^{3}}\right)
\end{array}
$$

in which $\mathbf{C}_{\mathbf{i}}$ is the concentration in the gas phase of each $\mathbf{i}$ species, $\mathbf{r}_{1}$ and $\mathbf{r}_{2}$ represent the reaction rates of each reaction, $\mathbf{k}_{\mathbf{1}}$ and $\mathbf{k}_{\mathbf{2}}$ correspond to the respective reaction rate constants, and $\mathbf{K}_{\mathbf{1}}$ and $\mathbf{K}_{\mathbf{2}}$ are the equilibrium constants, determined by thermodynamic data from Yaws [38].

As both of the reactions are equilibrium-based, it is important to take equilibrium into account. The issue of low methane conversion, which in a fixed bed system is typically $\sim 12 \%$ at $1000 \mathrm{~K}$, is caused by high equilibrium concentrations of 
hydrogen, which is produced in both reactions, pushing equilibrium toward the reactants. Removal of the hydrogen from the reactor would be one alternative to overcome this limitation. A membrane reactor would fit this role well. Membrane reactors are systems that enable process intensification by combining a reactor and a separator into one unit, allowing for higher process efficiency. They typically enable higher conversions due to the selective removal of product species through the membrane. For DMA, the reaction equilibrium is shifted toward the products when hydrogen is removed via a hydrogen-selective membrane. Membrane reactors present a challenging area of research due to modeling and design challenges as well as several process target specifications that need to be achieved.

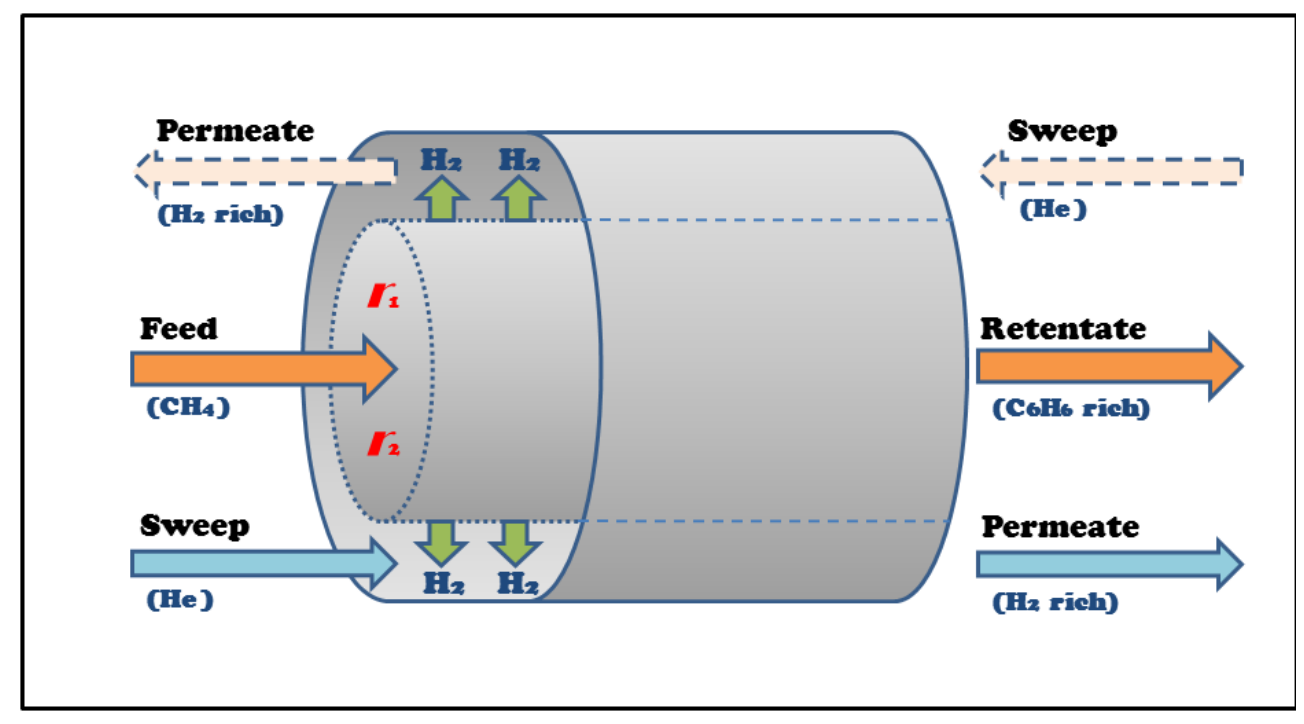

Figure 3: Membrane reactor co-current configuration [5].

A shell and tube membrane reactor design was considered for model development, shown in Figure 3, where methane feeds into the reactor side, the tube packed with catalysts, and the sweep gas, which in this case is helium $(\mathrm{He})$, flows through the shell, or permeation side. The hydrogen produced in the tube permeates 
into the shell through the membrane that surrounds the wall of the tube. The tube and shell outlet streams, the retentate and permeate, respectively, are rich in benzene and hydrogen, respectively.

In Equations 5-12, mass balances are given for the nonlinear membrane reactor model that represents this design.

Molar balances inside tube:

$$
\begin{aligned}
& \frac{\mathrm{dF}_{\mathrm{t}, \mathrm{CH}}}{\mathrm{dz}}=\mathbf{r}_{1} \mathrm{~A}_{\mathrm{t}}-\frac{\mathrm{Q}}{\alpha_{\mathrm{H}_{2} / \mathrm{CH}_{4}}}\left(\mathbf{p}_{\mathrm{t}, \mathrm{CH}}^{1 / 4}-\mathbf{p}_{\mathrm{s}, \mathrm{CH}_{4}}^{1 / 4}\right) \pi d_{t} \\
& \frac{\mathrm{dF}_{\mathrm{t}, \mathrm{C}_{2} \mathrm{H}_{4}}}{d z}=-\frac{\mathrm{r}_{1}}{2} A_{t}+r_{2} A_{t}-\frac{Q}{\alpha_{\mathrm{H}_{2} / \mathrm{C}_{2} \mathrm{H}_{4}}}\left(p_{t, \mathrm{C}_{2} \mathrm{H}_{4}}^{1 / 4}-p_{s, \mathrm{C}_{2} \mathrm{H}_{4}}^{1 / 4}\right) \pi d_{t} \\
& \frac{\mathrm{dF}_{\mathrm{t}, \mathrm{H}_{2}}}{\mathrm{dz}}=-\mathbf{r}_{1} A_{t}-r_{2} A_{t}-Q\left(p_{t, \mathrm{H}_{2}}^{1 / 4}-p_{s, \mathrm{H}_{2}}^{1 / 4}\right) \pi d_{t} \\
& \frac{\mathrm{dF}_{\mathrm{t}, \mathrm{C}_{6} \mathrm{H}_{6}}}{d z}=-\frac{\mathrm{r}_{2}}{3} A_{t}-\frac{Q}{\alpha_{\mathrm{H}_{2} / \mathrm{C}_{6} \mathrm{H}_{6}}}\left(p_{t, \mathrm{C}_{6} \mathrm{H}_{6}}^{1 / 4}-p_{s, \mathrm{C}_{6} \mathrm{H}_{6}}^{1 / 4}\right) \pi d_{t}
\end{aligned}
$$

Molar balances inside shell:

$$
\begin{aligned}
& \frac{\mathrm{dF}_{\mathrm{s}, \mathrm{CH}_{4}}}{\mathrm{dz}}=\frac{\mathrm{Q}}{\alpha_{\mathrm{H}_{2} / \mathrm{CH}_{4}}}\left(p_{\mathrm{t}, \mathrm{CH}_{4}}^{1 / 4}-p_{\mathrm{s}, \mathrm{CH}_{4}}^{1 / 4}\right) \pi d_{t} \\
& \frac{\mathrm{dF}_{\mathrm{s}, \mathrm{C}_{2} \mathrm{H}_{4}}}{d z}=\frac{Q}{\propto_{\mathrm{H}_{2} / \mathrm{C}_{2} \mathrm{H}_{4}}}\left(p_{t, \mathrm{C}_{2} \mathrm{H}_{4}}^{1 / 4}-p_{s, \mathrm{C}_{2} \mathrm{H}_{4}}^{1 / 4}\right) \pi d_{t} \\
& \frac{\mathrm{dF}_{\mathrm{s}, \mathrm{H}_{2}}}{\mathrm{dz}}=Q\left(p_{\mathrm{t}, \mathrm{H}_{2}}^{1 / 4}-p_{s, \mathrm{H}_{2}}^{1 / 4}\right) \pi d_{t} \\
& \frac{\mathrm{dF}_{\mathrm{s}, \mathrm{C}_{6} \mathrm{H}_{6}}}{d z}=\frac{Q}{\alpha_{\mathrm{H}_{2} / \mathrm{C}_{6} \mathrm{H}_{6}}}\left(p_{t, \mathrm{C}_{6} \mathrm{H}_{6}}^{1 / 4}-p_{s, \mathrm{C}_{6} \mathrm{H}_{6}}^{1 / 4}\right) \pi d_{t}
\end{aligned}
$$

where $\mathbf{F}_{\mathbf{t}, \mathbf{i}}$ and $\mathbf{F}_{\mathbf{s}, \mathbf{i}}$ are the molar flow rates for each species $\mathbf{i}$ inside the tube and the shell, respectively. The variables $\mathbf{z}, \mathbf{d}_{\mathbf{t}}$, and $\mathbf{A}_{\mathbf{t}}$ are the differential reactor length, diameter and cross-sectional area, respectively. The membrane flux expression is 
considered to be proportional to the membrane partial pressure gradient and has a $1 / 4$ order dependence associated with an ion-transport membrane. $\mathbf{Q}$ is the hydrogen permeance through the membrane, and $\boldsymbol{\alpha}_{\mathbf{H} 2 / \mathrm{i}}$ is the selectivity between hydrogen and species $\mathbf{i}$. $\mathbf{p}_{t, \mathbf{i}}$ and $\mathbf{p}_{\mathbf{s}, \mathbf{i}}$ are the partial pressures of components $\mathbf{i}$ in the tube and shell sides, respectively.

This initial model, which serves as the basis for this thesis, does not consider catalyst deactivation, that will be discussed below.

\subsection{Role of Selective Oxidation}

Cao et al. [2] and Yuan et al. [39] highlighted the usefulness of selective oxidation into the non-oxidative DMA system for dealing with catalyst deactivation. Those contributions are summarized below, along with information from Tempelman et al. $[27,28]$ describing some of the catalytic mechanisms.

The actual catalytic mechanism for DMA is still under research, but most studies agree that the mechanism for Mo-based catalysts begins with methane that goes through molybdenum carbide, where ethylene is formed, and then through the BAS on the zeolite support, where the ethylene is converted to aromatics. It has been hypothesized that coking begins when molybdenum carbide is formed within the pores of the zeolite, blocking access to the BAS for methane or keeping ethylene from exiting from the zeolite channels, forming both polyolefinic and polyaromatic cokes.

The oxidative DMA reaction is shown below in Equation 13.

R3:

$$
6 \mathrm{CH}_{4}+9 / 2 \mathrm{O}_{2} \rightarrow \mathrm{C}_{6} \mathrm{H}_{6}+9 \mathrm{H}_{2} \mathrm{O}
$$


It has been shown that the presence of oxygen and steam suppresses coke formation, and stoichiometric levels of oxygen inhibit formation of molybdenum carbide [2]. By slow introduction of oxygen through an oxygen-selective membrane, the catalyst deactivated within the same time span, but to a lesser degree. Less coke was formed, but most of the gained selectivity was not toward aromatics. The results of these experiments are shown in Figure 4. It is important to notice that coke production is decreased by $\sim 80-90 \%$ over several hours. However, most of the carbon goes to $\mathrm{CO}_{x}$ products, as opposed to benzene.
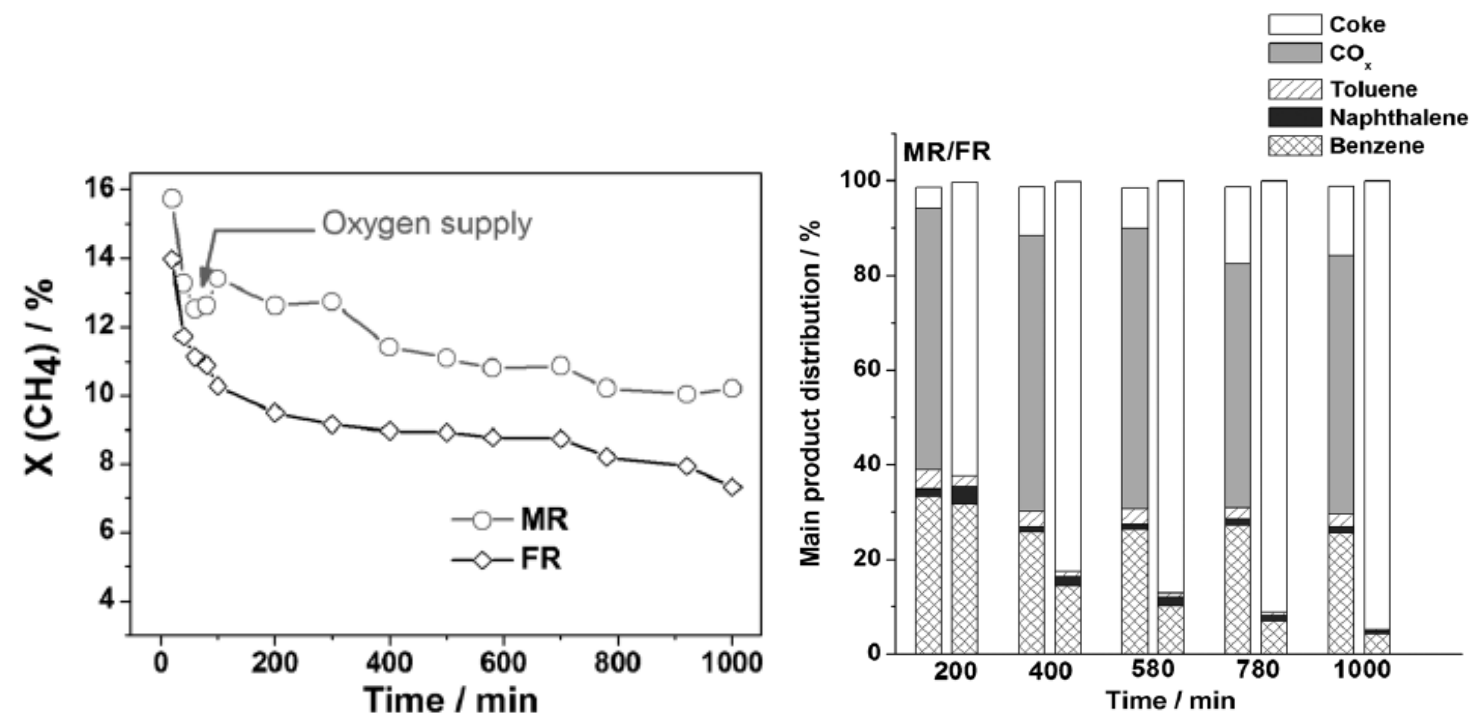

Figure 4: Methane conversion over time for membrane reactor (MR) and fixed-bed reactor (FR) (left). Product selectivity (right) [2].

As this experiment shows, catalyst deactivation can be inhibited to a large degree by oxygen entering the system. However, this additional feed allows many more side reactions to occur, further complicating the DMA system. 


\section{Proposed Approach}

The main objective in this research is to develop a model and an optimization study of a simulated DMA multifunctional membrane reactor system. The study will lead to more comprehensive models built for DMA, including the incorporation of additional reactions involving coke, naphthalene and oxygen, as well as the study of multifunctional membrane reactor designs and their performance.

\subsection{Reaction Modeling}

As shown above, the DMA system can be a complex mesh of reactions. Many studies do not include the multitude of interactions among species. The proposed reaction scheme allows for interactions between the standard non-oxidative DMA reactions with the oxidative DMA contributions and coke production. These steps are included to observe if the multifunctional membrane reactor design can help solve the issues presented above.

The non-oxidative DMA reaction scheme considered here is adapted from Li et al. [16] in which, along with Equations 1 and 2, naphthalene $\left(\mathrm{C}_{10} \mathrm{H}_{8}\right)$ is formed from ethylene and benzene, as shown in Equations 14 and 15. Naphthalene is treated as an undesired product for the DMA system.

R4:

$$
\begin{array}{r}
\mathrm{C}_{6} \mathrm{H}_{6}+2 \mathrm{C}_{2} \mathrm{H}_{4}=\mathrm{C}_{10} \mathrm{H}_{8}+3 \mathrm{H}_{2} \\
\mathbf{r}_{4}=\mathbf{k}_{4} \mathrm{C}_{\mathrm{C}_{6} \mathrm{H}_{6}} \mathrm{C}_{\mathrm{C}_{2} \mathrm{H}_{4}}\left(1-\frac{\mathrm{C}_{\mathrm{C}_{10} \mathrm{H}_{8}} \mathrm{C}_{\mathrm{H}_{2}}^{3}}{\mathrm{~K}_{4} \mathrm{C}_{\mathrm{C}_{2} \mathrm{H}_{4}}^{2} \mathrm{C}_{\mathrm{C}_{6} \mathrm{H}_{6}}}\right)
\end{array}
$$

Cao et al. [2] and Yuan et al. [39] both mention uncertainty in the actual schemes for the oxidative DMA reaction. They state that in the non-oxidative DMA system, ethylene formation from the molybdenum carbide may be the source of 
coking, so alternative mechanisms for methane to ethylene were explored. Two prominent routes to ethylene that have been proposed are partial oxidation and oxidative coupling of methane (OCM). Partial oxidation is typically used to produce syngas, and not olefins, so an OCM mechanism was selected to act as the alternative ethylene route in which oxygen is added to a non-oxidative DMA system. The full comprehensive OCM kinetic model from Stansch et al. [26] is used here to account for the oxidative DMA mechanism. This model introduces water and $\mathrm{CO}_{x}$ products into the system, as well as a water-gas shift reaction step, as detailed in Equations 16-31 below.

\begin{tabular}{|c|c|}
\hline R5: & $\mathrm{CH}_{4}+2 \mathrm{O}_{2} \rightarrow \mathrm{CO}_{2}+2 \mathrm{H}_{2} \mathrm{O}$ \\
\hline R6: & $2 \mathrm{CH}_{4}+0.5 \mathrm{O}_{2} \rightarrow \mathrm{C}_{2} \mathrm{H}_{6}+\mathrm{H}_{2} \mathrm{O}$ \\
\hline R7: & $\mathrm{CH}_{4}+\mathrm{O}_{2} \rightarrow \mathrm{CO}+\mathrm{H}_{2} \mathrm{O}+\mathrm{H}_{2}$ \\
\hline R8: & $\mathrm{CO}+\mathbf{0 . 5 O _ { 2 }} \rightarrow \mathrm{CO}_{2}$ \\
\hline R9: & $\mathrm{C}_{2} \mathrm{H}_{6}+0.5 \mathrm{O}_{2} \rightarrow \mathrm{C}_{2} \mathrm{H}_{4}+\mathrm{H}_{2} \mathrm{O}$ \\
\hline R10: & $\mathrm{C}_{2} \mathrm{H}_{4}+2 \mathrm{O}_{2} \rightarrow 2 \mathrm{CO}+2 \mathrm{H}_{2} \mathrm{O}$ \\
\hline R11: & $\mathrm{C}_{2} \mathrm{H}_{6} \rightarrow \mathrm{C}_{2} \mathrm{H}_{4}+\mathrm{H}_{2}$ \\
\hline R12: & $\mathrm{C}_{2} \mathrm{H}_{4}+2 \mathrm{H}_{2} \mathrm{O} \rightarrow 2 \mathrm{CO}+4 \mathrm{H}_{2}$ \\
\hline R13: & $\mathrm{CO}+\mathrm{H}_{2} \mathrm{O} \rightarrow \mathrm{CO}_{2}+\mathrm{H}_{2}$ \\
\hline 14: & $\mathrm{CO}_{2}+\mathrm{H}_{2} \rightarrow \mathrm{CO}+\mathrm{H}_{2} \mathrm{O}$ \\
\hline & 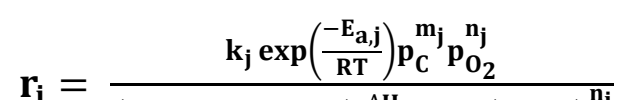 \\
\hline
\end{tabular}




$$
\begin{gathered}
\mathbf{r}_{6}=\frac{\mathbf{k}_{6} \exp \left(\frac{-\mathrm{E}_{\mathrm{a}, 6}}{\mathrm{RT}}\right)\left(\mathrm{K}_{\mathrm{ad}, 6, \mathrm{O}_{2}} \exp \left(\frac{-\Delta \mathrm{H}_{\mathrm{ad}, 6, \mathrm{O}_{2}}}{\mathrm{RT}}\right) \mathbf{p}_{\mathrm{O}_{2}}\right)^{\mathbf{n}_{6}} p_{C \mathrm{CH}_{4}}^{m_{6}}}{\left(1+\left(\mathrm{K}_{\mathrm{ad}, 6, \mathrm{O}_{2}} \exp \left(\frac{-\Delta \mathrm{H}_{\mathrm{ad}, 6, \mathrm{O}_{2}}}{\mathrm{RT}}\right) \mathbf{p}_{\mathrm{O}_{2}}\right)^{\mathbf{n}_{6}}+\mathrm{K}_{\mathrm{ad}, 6, \mathrm{CO}_{2}} \exp \left(\frac{-\Delta \mathrm{H}_{\mathrm{ad}, 6, \mathrm{CO}_{2}}}{\mathrm{RT}}\right) \mathbf{p}_{\mathrm{CO}_{2}}\right)^{2}} \\
\mathbf{r}_{11}=\mathbf{k}_{11} \exp \left(\frac{-\mathrm{E}_{\mathrm{a}, 11}}{\mathrm{RT}}\right) \mathbf{p}_{\mathrm{C}_{2} \mathrm{H}_{6}}^{\mathbf{m}_{11}} \\
\mathbf{r}_{12}=\mathbf{k}_{12} \exp \left(\frac{-\mathrm{E}_{\mathrm{a}, 12}}{\mathrm{RT}}\right) \mathbf{p}_{\mathrm{C}_{2} \mathrm{H}_{4}}^{\mathbf{m}_{12}} \mathbf{p}_{\mathrm{H}_{2} \mathrm{O}}^{\mathbf{n}_{12}} \\
\mathbf{r}_{13}=\mathbf{k}_{13} \exp \left(\frac{-\mathrm{E}_{\mathrm{a}, 13}}{\mathrm{RT}}\right) \mathbf{p}_{\mathrm{CO}_{13}}^{\mathbf{m}_{13} \mathbf{p}_{\mathrm{H}_{2} \mathrm{O}}^{\mathbf{n}_{13}}} \\
\mathbf{r}_{14}=\mathbf{k}_{14} \exp \left(\frac{-\mathrm{E}_{\mathrm{a}, 14}}{\mathrm{RT}}\right) \mathbf{p}_{\mathrm{CO} \mathrm{O}_{2}}^{\mathbf{m}_{14}} \mathbf{p}_{\mathrm{H}_{2}}^{\mathbf{n}_{14}}
\end{gathered}
$$

where $\mathbf{E}_{a, j}$ is the activation energy for reaction $\mathbf{j}, \mathbf{R}$ is the ideal gas constant, $\mathbf{T}$ is the system temperature, $\mathbf{p c}_{\mathrm{c}}$ is the partial pressure for the carbon-based reactant, $\mathrm{m}_{\mathrm{j}}$ and $\mathrm{n}_{\mathrm{j}}$ are exponential constants, $\mathbf{K}_{\mathbf{a d}, \mathrm{j}, \mathrm{i}}$ is the adsorption constant for species $\mathbf{i}, \boldsymbol{\Delta} \mathbf{H}_{\mathbf{a d}, \mathrm{j}, \mathrm{i}}$ is the adsorption energy.

There are no systems studies found to determine the kinetics of the coking mechanism specifically for a DMA system. In the developed model, it is assumed all the coking can be derived from an aromatics-to-soot pyrolysis model that includes oxygen effects, and the model from Fuentes-Cano et al. [8] is used with all relevant reactions and rates, summarized in Equations 32-38. All new reaction species (acetylene $\left[\mathrm{C}_{2} \mathrm{H}_{2}\right]$, pyrene $\left[\mathrm{C}_{16} \mathrm{H}_{10}\right]$, and elemental carbon[C]) added from this reaction scheme are considered as coking products in this model.

R15:

$$
\mathrm{C}_{2} \mathrm{H}_{4} \rightarrow \mathrm{C}_{2} \mathrm{H}_{2}+\mathrm{H}_{2}
$$

R16:

$$
\mathrm{C}_{10} \mathrm{H}_{8} \rightarrow 0.625 \mathrm{C}_{16} \mathrm{H}_{10}+0.875 \mathrm{H}_{2}
$$

R17:

$$
\mathrm{C}_{6} \mathrm{H}_{6} \rightarrow \mathrm{C}_{2} \mathrm{H}_{2}+0.25 \mathrm{C}_{16} \mathrm{H}_{10}+0.75 \mathrm{H}_{2}
$$


R18:

$$
\mathrm{C}_{16} \mathrm{H}_{10} \rightarrow 16 \mathrm{C}+5 \mathrm{H}_{2}
$$

R19:

$$
\begin{gathered}
\mathrm{CH}_{4}+\mathrm{H}_{2} \mathrm{O} \leftrightarrow \mathrm{CO}+3 \mathrm{H}_{2} \\
\mathbf{r}_{\mathbf{j}}=\mathbf{k}_{\mathrm{j}} \exp \left(\frac{-\mathrm{E}_{\mathrm{a}, \mathrm{j}}}{\mathrm{RT}}\right) \mathrm{C}_{\mathbf{i}} \\
\mathbf{r}_{19}=\mathbf{k}_{19} \exp \left(\frac{-\mathrm{E}_{\mathrm{a}, 19}}{\mathrm{RT}}\right) \mathrm{C}_{\mathrm{CH}_{4}} \mathrm{C}_{\mathrm{H}_{2} \mathrm{O}}
\end{gathered}
$$

\begin{tabular}{|c|c|c|c|c|c|c|c|c|c|}
\hline Reaction & $\begin{array}{c}\mathbf{k}_{\mathrm{j}} \\
\left(\mathrm{s}^{-1}\right)\end{array}$ & $\begin{array}{c}E_{\mathrm{a}, \mathrm{j}} \\
(\mathrm{kJ} / \mathrm{mol})\end{array}$ & $\mathrm{K}_{\mathrm{j}}$ & $\begin{array}{l}\mathrm{K}_{\mathrm{ad}, \mathrm{j}, \mathrm{CO} 2} \\
\left(\mathrm{~atm}^{-1}\right)\end{array}$ & $\begin{array}{l}\Delta \mathrm{H}_{\mathrm{ad}, \mathrm{j}, \mathrm{co} 2} \\
(\mathrm{~kJ} / \mathrm{mol})\end{array}$ & $\begin{array}{c}\mathrm{K}_{\mathrm{ad}, \mathrm{O} 2} \\
\left(\mathrm{~atm}^{-1}\right)\end{array}$ & $\begin{array}{c}\Delta \mathrm{H}_{\mathrm{ad}, \mathrm{j}, \mathrm{O} 2} \\
(\mathrm{~kJ} / \mathrm{mol})\end{array}$ & $m_{j}$ & $\mathbf{n}_{\mathrm{j}}$ \\
\hline 1 & 0.04 & - & $6.91 \times 10^{-7}$ & - & - & - & - & - & - \\
\hline 2 & 4.2 & - & 840 & - & - & - & - & - & - \\
\hline 4 & $1.2 \times 10^{7 *}$ & - & 1.15 & - & - & - & - & - & - \\
\hline 5 & $2.03 \times 10^{-4 \#}$ & 48 & - & $2.53 \times 10^{-8}$ & -175 & - & - & 0.24 & 0.76 \\
\hline 6 & $2.36 \times 10^{5}$ & 182 & - & $8.41 \times 10^{-9}$ & -186 & $2.33 \times 10^{-7}$ & -124 & 1.0 & 0.40 \\
\hline 7 & $6.67 \times 10^{-3}$ & 68 & - & $3.65 \times 10^{-9}$ & -187 & - & - & 0.57 & 0.85 \\
\hline 8 & 6.31 & 104 & - & $4.05 \times 10^{-8}$ & -168 & - & - & 1.0 & 0.55 \\
\hline 9 & 689 & 157 & - & $4.56 \times 10^{-8}$ & -166 & - & - & 0.95 & 0.37 \\
\hline 10 & $3.88 \times 10^{5}$ & 166 & - & $1.62 \times 10^{-8}$ & -211 & - & - & 1.0 & 0.96 \\
\hline 11 & $1.22 \times 10^{12+}$ & 226 & - & - & - & - & - & 1.0 & - \\
\hline 12 & $6.67 \times 10^{5}$ & 300 & - & - & - & - & - & 0.97 & 0 \\
\hline 13 & $1.95 \times 10^{3}$ & 173 & - & - & - & - & - & 1.0 & 1.0 \\
\hline 14 & $2.67 \times 10^{5}$ & 220 & - & - & - & - & - & 1.0 & 1.0 \\
\hline 15 & $5.01 \times 10^{5}$ & 155 & - & - & - & - & - & - & - \\
\hline 16 & $1.94 \times 10^{13}$ & 326 & - & - & - & - & - & - & - \\
\hline 17 & $2.14 \times 10^{10}$ & 264 & - & - & - & - & - & - & - \\
\hline 18 & $7.94 \times 10^{23}$ & 536 & - & - & - & - & - & - & - \\
\hline 19 & $3.0 \times 10^{5 *}$ & 125 & - & - & - & - & - & - & - \\
\hline
\end{tabular}

where $\mathbf{C}_{\mathbf{i}}$ is the concentration of the reactant $\mathbf{i}$ in reaction $\mathbf{j}$.

All kinetic parameters used in this model are defined below in Table 1.

Table 1. Kinetic model parameters for DMA, OCM, and pyrolysis reactions mechanisms.

\subsection{Membrane Modeling}

The developed multifunctional membrane model employs two membranes in one system that separate oxygen from air and hydrogen from the reaction zone. Thus, there are three zones in the model based on the membrane reactor design shown in Figure 5: the reaction zone, where the feed methane is introduced and all the reactions take place; the outer shell, where helium is introduced as a sweep gas and carries separated hydrogen removed from the reaction zone via the hydrogen- 
permeable membrane (M1); and the inner tube, where air enters and the oxygen from the air passes through the oxygen-permeable membrane (M2) to the reaction zone.

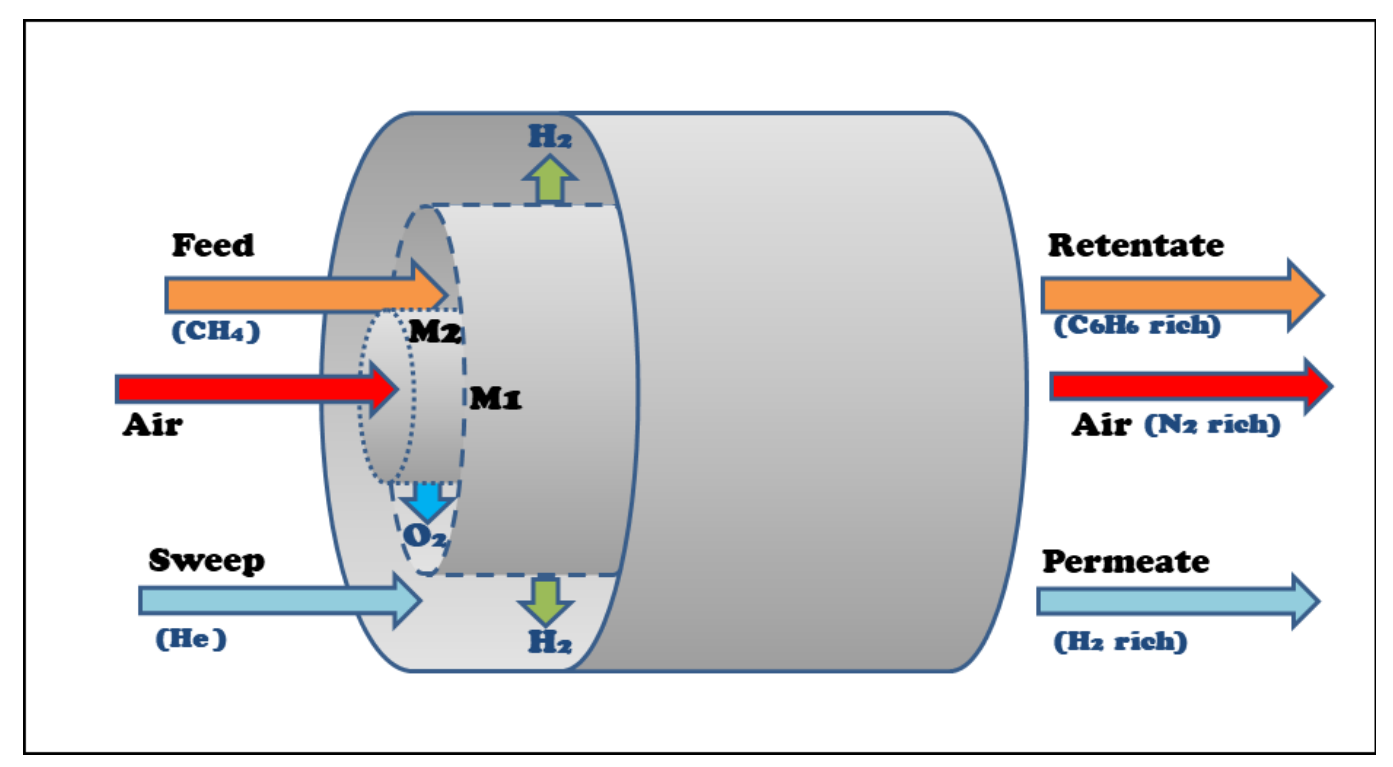

Figure 5. Multifunctional membrane reactor design for DMA.

The membrane reactor model used here for simulation and performance assessment studies is a one-dimensional, isothermal model that operates at steadystate and where all flows are co-current with respect to the feed stream. These assumptions are for a reasonable estimation of operation for a laboratory-scale membrane reactor. The basis for this model is the model presented above in Equations 5-12. Assuming plug-flow operation, the membrane reactor model considers species mole balances, as summarized in Equations 39-41:

Mole balance, reaction zone:

$$
\frac{d F_{r, i}}{d z}=r_{j, i} A_{r}+J_{i, 1} \pi d_{1}+J_{i, 2} \pi d_{2}
$$

where $\mathbf{F}_{\mathbf{r}, \mathrm{i}}$ is the flow rate of species $\mathbf{i}$ in the reaction zone, $\mathbf{z}$ is the discrete reactor length, $\mathbf{r}_{\mathrm{j}, \mathrm{i}}$ is the species reaction rate corresponding to reaction step $\mathbf{j}, \mathbf{A}_{\mathbf{r}}$ is the cross- 
sectional area of the reaction zone, $\mathbf{J}_{\mathrm{i}, 1}$ and $\mathrm{J}_{\mathrm{i}, 2}$ are the molar fluxes across the membrane walls of $\mathrm{M} 1$ and $\mathrm{M} 2$, respectively, and $\mathbf{d}_{1}$ and $\mathbf{d}_{2}$ are the diameters of the tubes for M1 and M2, respectively. For elemental carbon in the reactor, $\mathbf{J i}_{\mathbf{i}, \mathbf{1}}=\mathbf{J}_{\mathbf{i}, 2}=0$ is assumed due to its solid phase. The sign of the molar fluxes depends on the partial pressure differences, shown below in Equations 42 and 43 . The sign for the species reaction rate is positive for products and negative for reactants.

Mole balances, outer shell and inner tube, respectively:

$$
\begin{aligned}
& \frac{\mathrm{dF}_{\mathrm{M} 1, \mathrm{i}}}{\mathrm{dz}}=\mathrm{J}_{\mathrm{i}, \mathbf{1}} \pi \mathrm{d}_{\mathbf{1}} \\
& \frac{\mathrm{d \textrm {F } _ { \mathrm { M } 2 , \mathrm { i } }}}{\mathrm{dz}}=\mathrm{J}_{\mathrm{i}, 2} \pi \mathrm{d}_{\mathbf{2}}
\end{aligned}
$$

where $\mathbf{F}_{\mathbf{M} 1, \mathbf{i}}$ and $\mathbf{F}_{\mathbf{M} 2, \mathbf{i}}$ are the flow rates in the outer shell and inner tube, respectively. The resulting model can be solved using an ODE initial-value problem solver. In this thesis, MATLAB subroutine "ode15s" was used.

The model for $\mathrm{M} 1$ is based on a $\mathrm{SrCe}_{0.9} \mathrm{Eu}_{0.1} \mathrm{O}_{3-\delta}$ (SCE) ion-transport membrane. The flux through $\mathrm{M} 1$ is assumed to have a $1 / 4$ order dependence on partial pressure, as shown in Equation 42, in accordance with Equations 5-12:

$$
\mathrm{J}_{\mathrm{i}, \mathbf{1}}=\frac{\mathrm{Q}_{1}}{\alpha_{\mathrm{i}, 1}}\left(\mathbf{p}_{\mathrm{r}, \mathrm{i}}^{\frac{1}{4}}-\mathbf{p}_{\mathrm{M} 1, \mathrm{i}}^{\frac{1}{4}}\right)
$$

where $\mathbf{Q}_{1}$ is the permeance of hydrogen through $M 1, \boldsymbol{\alpha}_{i, 1}$ is the selectivity of species $\mathbf{i}$ to hydrogen for $\mathrm{M} 1$, and $\mathbf{p}_{\mathrm{r}, \mathrm{i}}$ and $\mathbf{p}_{\mathbf{M} 1, \mathrm{i}}$ are the partial pressures of each species in the reaction zone and $\mathrm{M} 1$, respectively. 
The model for $\mathrm{M} 2$ was derived from [20] for a $\mathrm{La}_{2} \mathrm{NiO}_{4+\delta}(\mathrm{LNO})$ ion-transport membrane. The flux through M2 is also assumed to have a $1 / 4$ order dependence on partial pressure, as well as a temperature dependence, as shown in Equation 43:

$$
\mathbf{J}_{\mathrm{i}, 2}=\frac{\mathbf{Q}_{2}}{\alpha_{\mathrm{i}, 2}} \exp \left(\frac{-\mathbf{B}}{\mathrm{T}}\right)\left(\mathbf{p}_{\mathrm{r}, \mathrm{i}}^{\frac{1}{4}}-\mathbf{p}_{\mathrm{M} 2, \mathrm{i}}^{\frac{1}{4}}\right)
$$

where $\mathbf{Q}_{\mathbf{2}}$ is the permeance of oxygen through $\mathrm{M} 2, \boldsymbol{\alpha}_{\mathbf{i}, 2}$ is the selectivity of species i to oxygen for $\mathrm{M} 2$, $\mathbf{p}_{\mathbf{M} 2, \mathrm{i}}$ is the partial pressure of each species in M2, $\mathbf{B}$ is an effective activation energy for $\mathrm{M} 2$, and $\mathbf{T}$ is the system temperature.

\subsection{Simulation and Optimization Setup}

The reactor feed, assumed to be pure methane, and the helium sweep molar flow rates are taken from Carrasco and Lima [3]. The helium sweep and the air feeds are assumed to be pure as well. Air is fed in excess to ensure oxygen flux over the entire length of the reactor. The reactor is held at $1050 \mathrm{~K}$ and is assumed to be temperature controlled with the presence of a furnace. It is also assumed to have negligible pressure drop over the length of the reactor. The base case design conditions are shown in Table 2, in which $\mathbf{Q}_{\mathbf{2}}$ and $\mathbf{B}$ are taken from Mancini and Mitsos [20]. This base case design is used to simulate and validate the use of the multifunctional membrane reactor. Coking is assumed to have no effect on the membrane transport. 
Table 2. Base case simulation design and process conditions.

\begin{tabular}{|c|c|c|c|}
\hline Parameter (unit) & Value & Parameter (unit) & Value \\
\hline Temperature (K) & 1,050 & $\mathbf{d}_{2}(\mathrm{~cm})$ & 0.5 \\
\hline Pressure (atm) & 1 & $\mathbf{Q}_{1}\left(\mathrm{~mol} / \mathrm{s} \cdot \mathrm{m}^{2} \cdot \mathrm{atm}^{1 / 4}\right)$ & 0.01 \\
\hline$F_{\mathrm{CH} 4 \text {,feed }}(\mathrm{mmol} / \mathrm{h})$ & 4.98 & $\mathbf{Q}_{2}\left(\mathrm{~mol} / \mathrm{s} \cdot \mathrm{m}^{2} \cdot \mathrm{atm}^{1 / 4}\right)$ & $1.3 \times 10^{-3}$ \\
\hline$F_{\text {air,feed }}(\mathrm{mmol} / \mathrm{h})$ & 23.8 & $\boldsymbol{\alpha}_{\mathrm{i}, 1}\left(\mathrm{H}_{2} /\right.$ all $)$ & $10^{6}$ \\
\hline$F_{\text {He,sweep }}(\mathrm{mmol} / \mathrm{h})$ & 6.24 & $\boldsymbol{\alpha}_{\mathrm{i}, 2}\left(\mathrm{O}_{2} /\right.$ all $)$ & $10^{6}$ \\
\hline $\begin{array}{l}L(\mathrm{~cm}) \\
d_{1}(\mathrm{~cm})\end{array}$ & $\begin{array}{c}25 \\
1.25\end{array}$ & $D(6)$ & 10,240 \\
\hline
\end{tabular}

The operational performance of the reactor is analyzed below with a multivariable operability-based AIS/AOS (available input set/achievable output set) mapping study, as in Carrasco and Lima [3-5]. Sensitivity studies are also performed to determine the largest contributing design variables in the system. In such studies, the reactor size is varied in length and diameter simultaneously, while membrane design conditions for $\mathrm{M} 1\left(\mathbf{Q}_{\mathbf{1}}\right.$ and $\left.\boldsymbol{\alpha}_{\mathrm{i}, 1}\right)$ are also changed to initially produce twodimensional input analyses. Then all four of the above design parameters are varied to determine the best design for a DMA system via this model.

In order to determine the best design, three performance criteria are set as maximum methane conversion and benzene production rate, with minimal coking products in addition to the constraint for plug flow reactor operation. These are defined below as Equations 44-47, respectively:

$\mathrm{CH}_{4}$ conversion $\left(\mathrm{X}_{\mathrm{CH}}\right)$ :

$$
\mathbf{X}_{\mathrm{CH} 4}=\frac{\mathrm{CH}_{4} \text { converted }}{\mathrm{CH}_{4} \text { in feed }}=\frac{\mathrm{F}_{\mathrm{r}, \mathrm{CH} 4, \mathrm{feed}}-\left(\mathrm{F}_{\mathrm{r}, \mathrm{CH} 4, \mathrm{end}}+\mathrm{F}_{\mathrm{M} 1, \mathrm{CH} 4, \text { end }}+\mathrm{F}_{\mathrm{M} 2, \mathrm{CH} 4, \mathrm{end}}\right)}{\mathrm{F}_{\mathrm{r}, \mathrm{CH} 4, \mathrm{feed}}} \times 100 \%
$$

$\mathrm{C}_{6} \mathrm{H}_{6}$ production rate $\left(\mathrm{F}_{\mathrm{C} 6 \mathrm{H} 6}\right)$ :

$$
\mathrm{F}_{\mathrm{C6H6}}=\mathrm{F}_{\mathrm{r}, \mathrm{C6H6}, \mathrm{end}}\left[\frac{\mathrm{mg}}{\mathrm{h}}\right]
$$


Coking products $\left(\mathrm{C}_{\mathrm{c}}\right)$ :

$$
\mathrm{C}_{\mathrm{C}}=\frac{\text { carbon from coke products }}{\text { carbon in feed }}=\frac{\mathrm{F}_{\mathrm{C}, \text { end }}+\mathrm{F}_{\mathrm{C} 2 \mathrm{H} 2, \text { end }}+\mathrm{F}_{\mathrm{C} 16 \mathrm{H} 10, \mathrm{end}}}{\mathrm{F}_{\mathrm{CH} 4, \mathrm{r}, \text { feed }}} \times 100 \%
$$

Reactor dimension requirement for plug flow in reaction zone [22]:

$$
\mathbf{L} / \mathbf{d}_{\mathbf{h}} \geq \mathbf{1 5}
$$

where $d_{h}$ is the hydraulic diameter for an annulus, defined in Equation 48 below:

$$
d_{h}=d_{1}-d_{2}
$$

The design is optimized using a grid search method over normalized performance criteria, so that each performance criteria had equal weight in the objective function $\boldsymbol{\varphi}$, as shown in Equation 49:

$$
\varphi=\max \left[\frac{\mathrm{x}_{\mathrm{CH} 4}}{\mathrm{x}_{\mathrm{CH} 4 \text { max }}}+\frac{\mathrm{F}_{\mathrm{C} 6 \mathrm{H} 6}}{\mathrm{~F}_{\mathrm{C} 6 \mathrm{H} 6, \max }}+\left(1-\frac{\mathrm{C}_{\mathrm{C}}}{\mathrm{C}_{\mathrm{C}, \max }}\right)\right]
$$

where the max subscript denotes the maximum value observed for the corresponding performance criteria through extensive simulations.

\section{Results and Discussion}

\subsection{Base Case Performance Studies}

The performance of the multifunctional membrane reactor is initially assessed using the design and process conditions in Table 2. First, a tubular reactor accounting for no membrane implementation is simulated in order to determine the base case results. The hydrogen-permeable membrane and the oxygen-permeable membrane are then accounted for in separate simulations to show the effects of each in terms of 
process improvement. Finally, both membranes are placed in tandem. The results of these simulations are summarized below in Table 3.

Table 3. Base case performance criteria results. Base uses no membrane, $\mathrm{M} 1$ uses $\mathrm{H}_{2}$ permeable membrane, $\mathrm{M} 2$ uses $\mathrm{O}_{2}$-permeable membrane, and Multifunctional uses both membranes.

\begin{tabular}{ccccc}
\hline Output (unit) & Base & M1 & M2 & Multifunctional \\
\hline $\mathbf{X}_{\mathrm{CH4}}(\%)$ & 19.52 & 38.36 & 19.57 & 38.15 \\
$\mathbf{F}_{\mathrm{C6H} 6}(\mathrm{mg} / \mathrm{h})$ & 10.49 & 19.85 & 8.65 & 18.09 \\
$\mathbf{C C}_{\mathrm{c}}(\%)$ & 2.28 & 4.95 & 2.06 & 4.64 \\
\hline
\end{tabular}

In the base tubular reactor without membrane, it is shown that coke products are formed with the desired products in the operation of this system, as expected. Whenever M1 is added to the system, the methane conversion increases dramatically, but the coking effects also increase by a similar factor. The conversion increase is largely due to the removal of hydrogen in the system, shifting the DMA equilibrium as described above. The coking effects increase due to increases in benzene and ethylene production, both of which contribute to the pyrolysis model in Fuentes-Cano [8].

When M2 is added to the tubular reactor system, the conversion increases slightly, while the coking effects decrease by $\sim 10 \%$ when compared to the base case. This fact is consistent with the reported role of oxygen in coking inhibition for the DMA system. This inhibition would potentially be higher if the dynamic operation of the reactor was considered. Benzene production also decreases due to the carbon usually reserved for benzene going to other sources, such as $\mathrm{CO}_{x}$ products. The benzene production loss could be an issue with this design, but a cost analysis would need to be done to compare the tradeoffs with the reduction in coking effects. 
When both membranes are added to the base case tubular system, the coking effects decrease by less than $~ 10 \%$ when compared to the case with M1 only, similar to the effect observed when M2 was added to the tubular system without membrane. The conversion again increases dramatically when compared to the base case and the scenario with M2 only. These results show that the two effects of increased conversion and coking inhibition have potential to be enhanced in a single system to different degrees depending on the performance criteria of interest.

\subsection{Sensitivity Studies}

In order to analyze each individual effect of the design variables and determine the variables with the greatest contributions to the performance criteria, sensitivity studies are performed. Table 4 shows the ranges for each variable considered in these studies. In each study, all other variables are constant at similar values to the base case parameters other than the variables of interest. Both membranes can be highly selective due to their ionic nature, and in this model, it is assumed that M2 is completely selective to oxygen, as stated in Mancini and Mitsos [20]. The selectivity of the other membrane $\mathrm{M} 1, \boldsymbol{\alpha}_{\mathrm{i}, 1}$, is considered as a design variable.

Table 4. Sensitivity study input variable ranges.

\begin{tabular}{cc}
\hline Parameter (unit) & Range \\
\hline $\mathbf{L}(\mathrm{cm})$ & $20-200$ \\
$\mathbf{d}_{1}(\mathrm{~cm})$ & $0.5-3$ \\
$\mathbf{d}_{2}(\mathrm{~cm})$ & $0.2-2$ \\
$\mathbf{Q}_{1}\left(\mathrm{~mol} / \mathrm{s}^{2} \mathrm{~m}^{2} \cdot \mathrm{atm}^{1 / 4}\right)$ & $10^{-6}-0.1$ \\
$\mathbf{Q}_{\mathbf{2}}\left(\mathrm{mol} / \mathrm{s}^{2} \mathrm{~m}^{2} \cdot \mathrm{atm}^{1 / 4}\right)$ & $10^{-7}-10^{-2}$ \\
$\mathbf{a}_{\mathrm{i}, 1}\left(\mathrm{H}_{2} / \mathrm{all}\right)$ & $10^{2}-10^{7}$ \\
\hline
\end{tabular}


The reactor length ( $\mathbf{L})$, along with $\mathbf{d}_{\mathbf{1}}, \mathbf{Q}_{\mathbf{1}}, \mathbf{Q}_{\mathbf{2}}$, and $\boldsymbol{\alpha}_{\mathbf{i}, \mathbf{1}}$ significantly affect all three performance criteria. The permeance through $\mathrm{M}_{2}, \mathbf{Q}_{2}$, has a decreasing effect on coke and benzene production when permeance, or oxygen flux, is higher than the base case conditions, as seen in Figure 6. This means oxygen addition has a significant negative effect on benzene production due to selectivity to OCM products. Too much oxygen in the system leads reactants away from the DMA scheme, highlighting why slow addition of oxygen through the membrane is necessary to take advantage of the coke inhibition. Conversion increases with permeance due to more reactions occurring that consume methane. The purpose of the M2 membrane was to inhibit coke, so for the rest of the studies, $\mathbf{Q}_{\mathbf{2}}=1.3 \times 10^{-3}$ was chosen, as in the base case and in Mancini and Mitsos [20], corresponding to a relatively low coke production value.
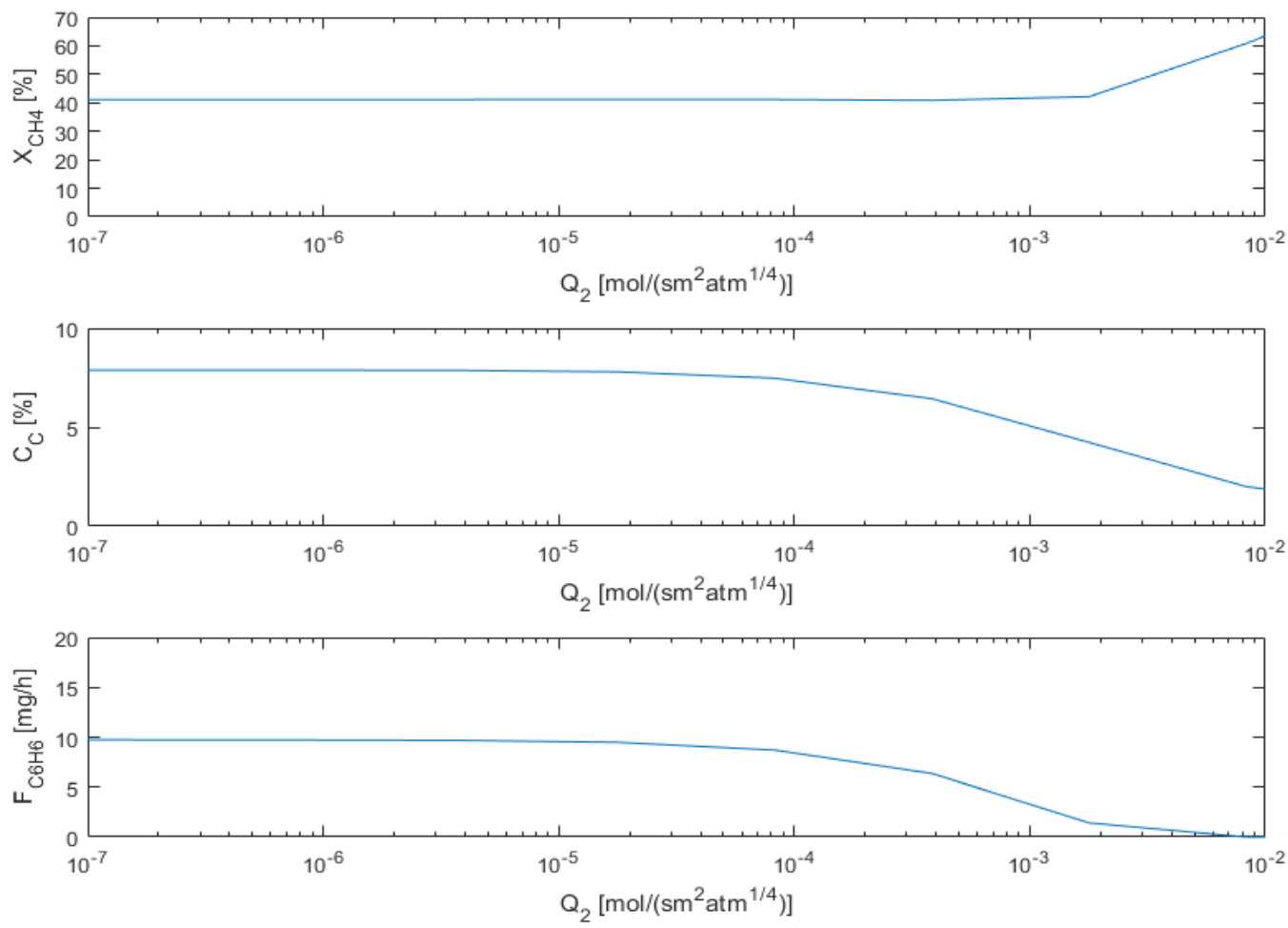

Figure 6. Sensitivity studies of $\mathbf{Q}_{2}$ for model performance criteria: $\mathbf{X}_{\mathbf{c H} 4}$ (top), $\mathbf{C}_{c}$ (middle), $\mathbf{F}_{\mathbf{c} 6 \mathrm{H} 6}$ (bottom). 
Studying the M2 diameter $\left(\mathbf{d}_{2}\right)$, however, presents an interesting problem as it is the inside diameter of the reaction zone annulus. If $\mathbf{d}_{2}$ is simply increased with constant $d_{1}$ and as $d_{1}$ is always greater than $d_{2}$, assuming $d_{1}=2.5 \mathrm{~cm}$, as shown in Figure 7, the cross-sectional area $\left(\mathbf{A r}_{\mathbf{r}}\right)$ of the reaction zone decreases, which greatly affects the molar balances in the model. Coke production is the only criteria that significantly changes, decreasing while $\mathbf{d}_{2}$ increases. This is partially due to the decrease in $\mathbf{A}_{r}$, while also possibly due to increased oxygen flux through M2, as evidenced by the relatively constant benzene production. This increased flux may allow for more selectivity of OCM products over coke products, while not affecting the benzene production. Thus, increasing $\mathbf{d}_{2}$ with constant $\mathbf{d}_{\mathbf{1}}$ is one representation of the effects of the M2 and the oxygen addition on the performance criteria, but it may not be the clearest representation. So, this case and three alternative cases are analyzed to determine what may give the clearest representation. Case 1 uses constant $\mathbf{d}_{1}$ while varying $d_{2}$, as discussed above. Case 2 uses a constant $A r=1 \mathrm{~cm}^{2}$ as $d_{2}$ is varied. It is possible to see in Figure 8 that coke production and conversion are essentially constant when $\mathbf{A}_{\mathbf{r}}$ is constant, meaning that the increased oxygen flux through M2 does not have a significant effect on the system. Benzene production does decrease, but this is due to the increased flux through M1 as $d_{1}$ is also increasing. The final study, Case 3 uses a constant $\mathbf{d}_{1} / \mathbf{d}_{2}=2$ while $\mathbf{d}_{2}$ is varied, seen in Figure 9. Here, the coke production significantly increases with diameter due to $\mathbf{A r}$ increasing over the study, enlarging the volume for the reaction to take place. Benzene production decreases due to increase in M1 permeation from increasing $\mathbf{d}_{1}$. This case thus mainly shows the effects of $\mathbf{d}_{1}$ increasing, rather than $\mathbf{d}_{2}$, on the performance criteria. 

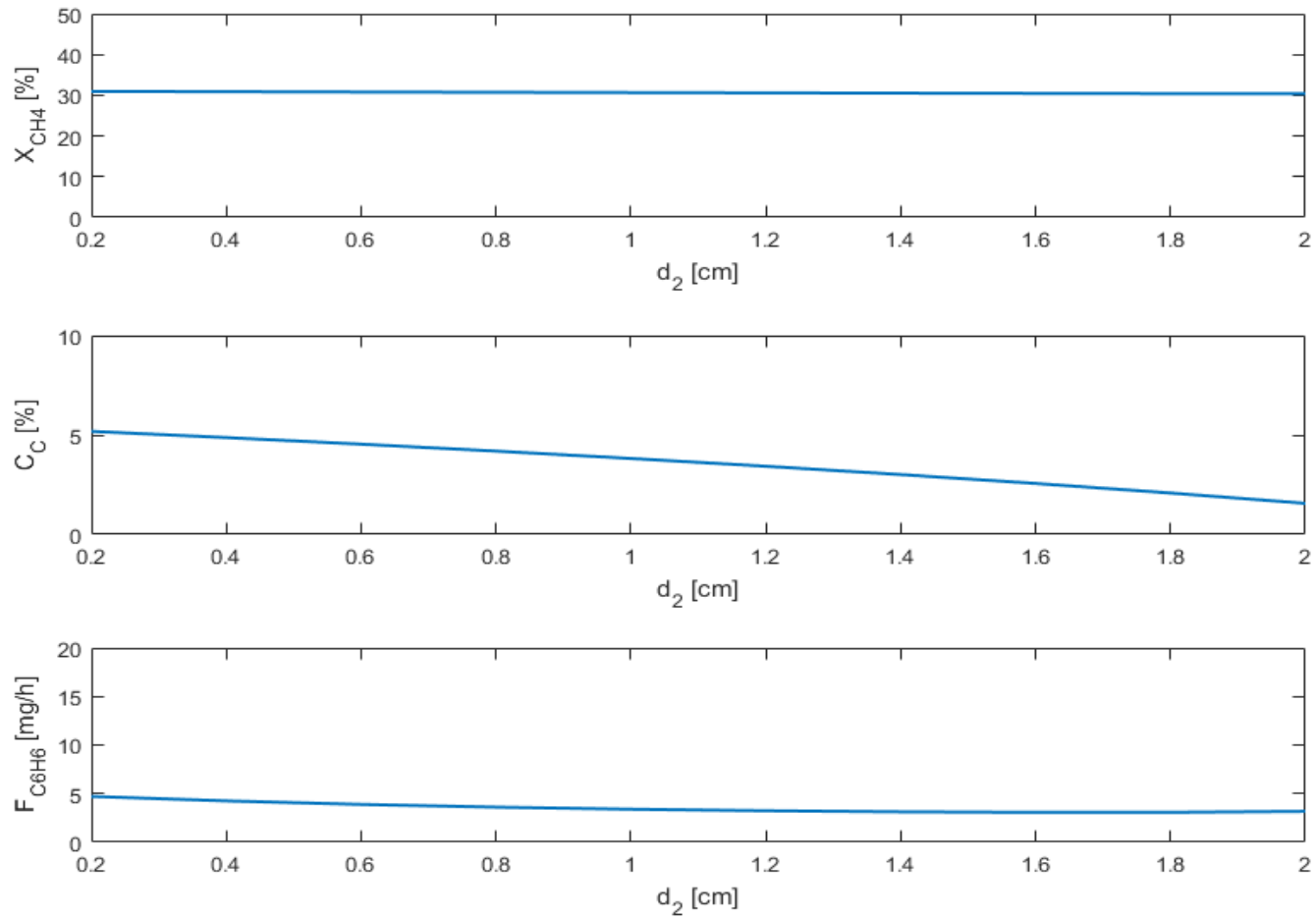

Figure 7. Case 1 study of $\mathbf{d}_{2}$ for model performance criteria: $\mathbf{X}_{\mathbf{c H} 4}$ (top), $\mathbf{C}_{\mathbf{c}}$ (middle), $\mathbf{F}_{\mathbf{c} 6 \mathrm{H} 6}$ (bottom).
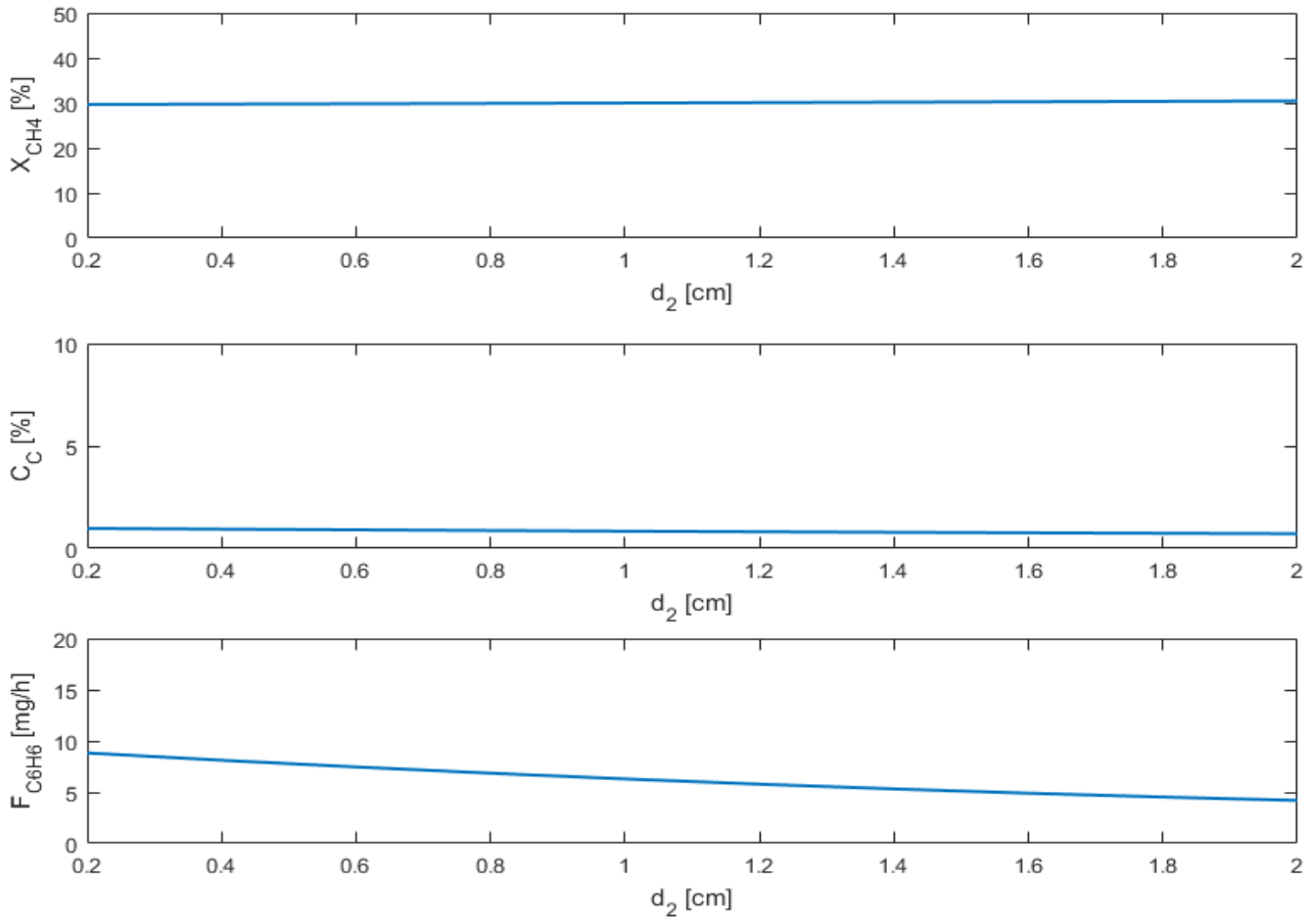

Figure 8. Case 2 study of $\mathbf{d}_{2}$ for model performance criteria: $\mathbf{X}_{\mathbf{c H} 4}$ (top), $\mathbf{C}_{c}$ (middle), $\mathbf{F}_{\mathbf{c} 6 \mathrm{H} 6}$ (bottom). 

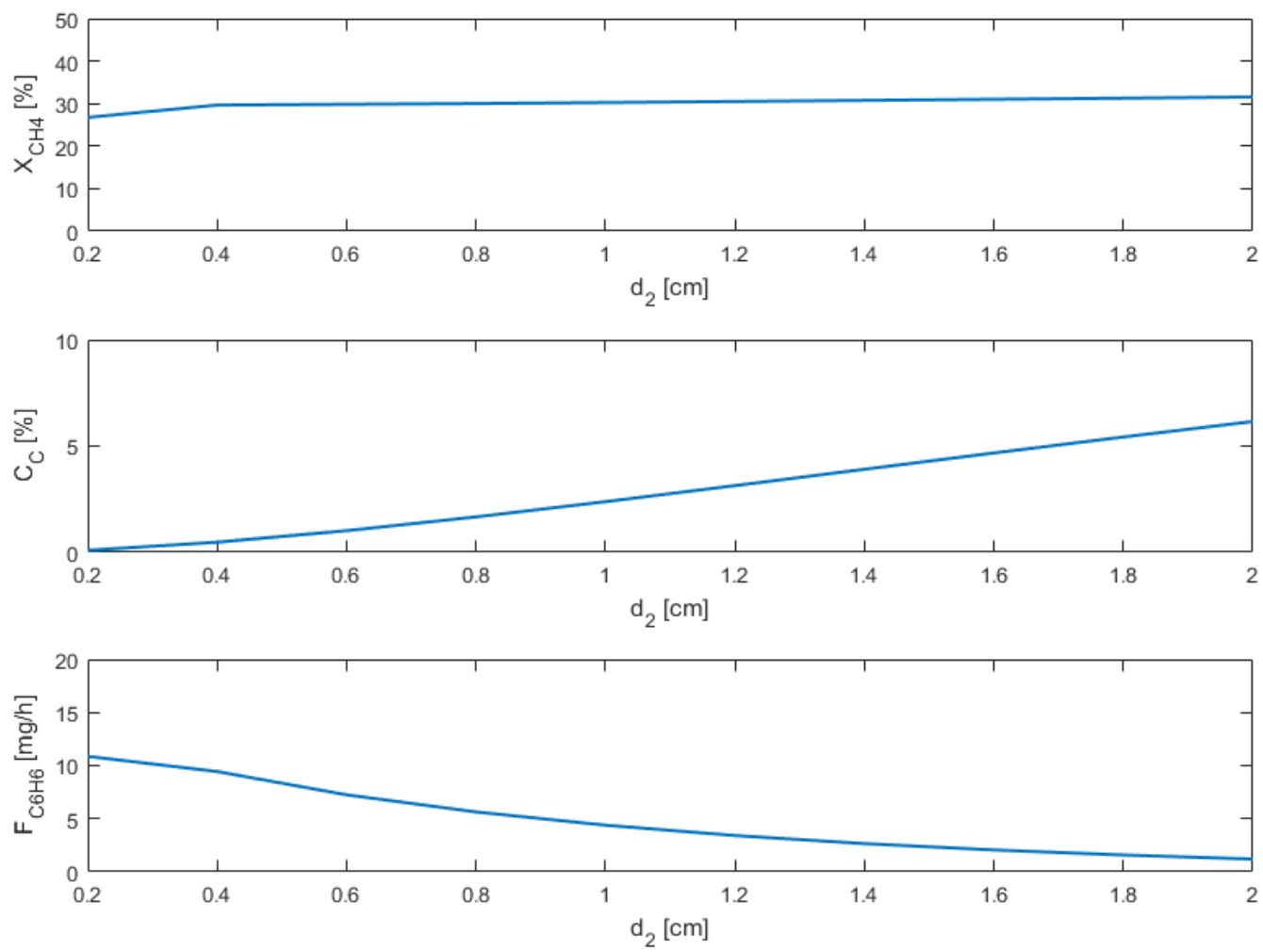

Figure 9. Case 3 study of $\mathbf{d}_{2}$ for model performance criteria: $\mathbf{X}_{\mathbf{c H} 4}$ (top), $\mathbf{C}_{\mathbf{c}}$ (middle), $\mathbf{F}_{\mathbf{c} 6 \mathrm{H} 6}$ (bottom).

Case 2 provides the simplest explanation of the effect $\mathbf{d}_{2}$ has on the performance criteria, showing that the design of the M2 membrane at the set permeance has no significant effect in this steady-state model. However, the presence of oxygen in the system still leads to some coking inhibition, as shown above in the base case studies. Due to low effects of this variable on the other performance criteria, the low, fixed value of $0.25 \mathrm{~cm}$ is chosen for $\mathbf{d}_{2}$ for the rest of the studies. This low $\mathbf{d}_{2}$ value is chosen to allow for $\mathbf{d}_{1}$ to change according to the range in Table 4 .

Reactor length (L) shows to be the most significant design variable among those selected, shown in Figure 10, as coke production ratio can reach nearly $10 \%$ at long lengths, while benzene production is hindered as well at long lengths. This is due to the DMA reactions reaching equilibrium within a short distance in the reactor. The 
coking effects increase and the benzene production is inhibited with length due to the increased volume for pyrolysis and benzene permeation through M1. This result indicates that the reactor design should be short in length to take both factors into account.
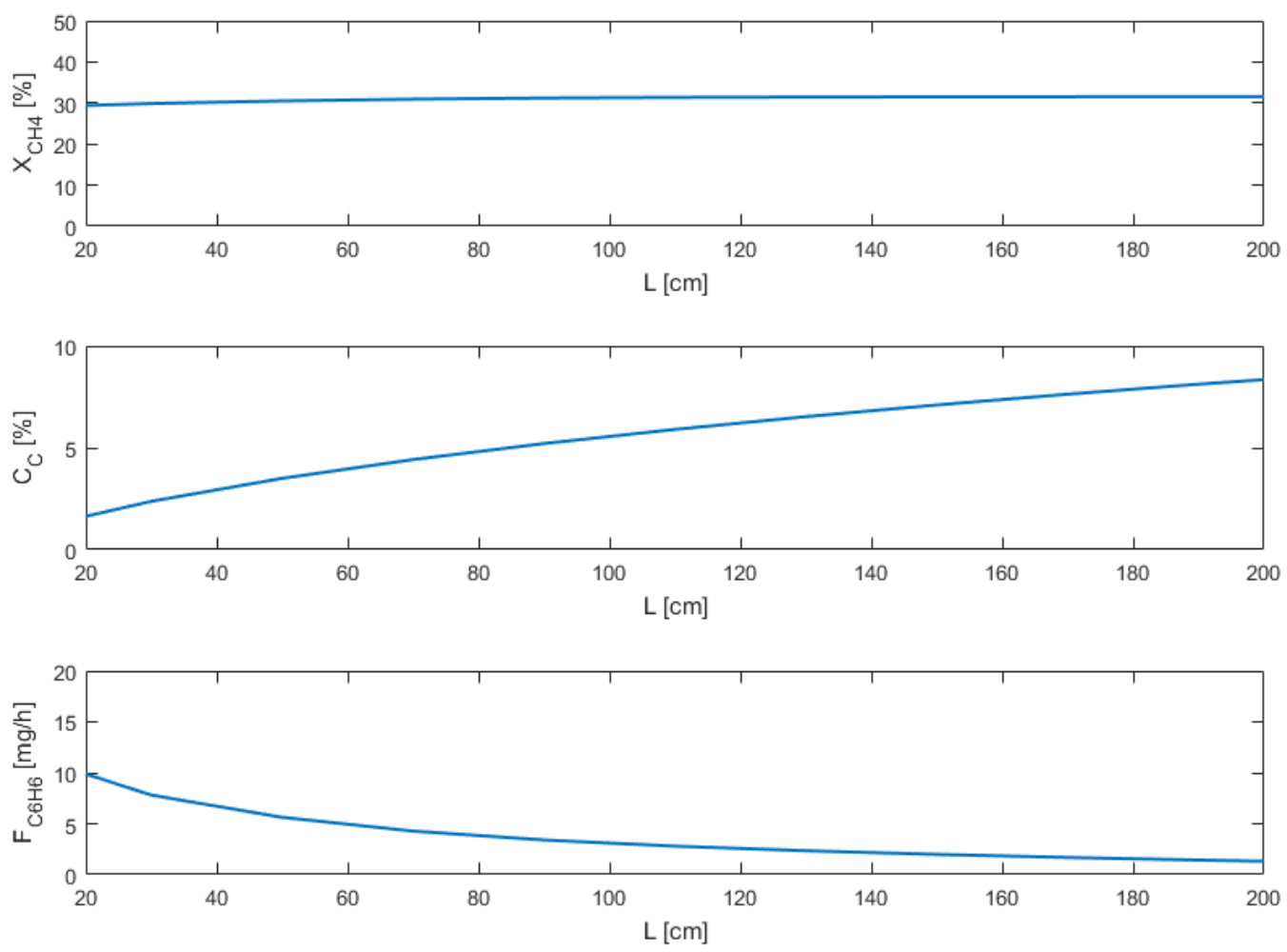

Figure 10. Sensitivity studies of $\mathbf{L}$ for model performance criteria: $\mathbf{X}_{\mathbf{c H} 4}$ (top), $\mathbf{C}_{\mathbf{c}}$ (middle), $\mathbf{F}_{\mathbf{c} 6 \mathbf{H} 6}$ (bottom).

The diameter of M1 ( $\left.\mathbf{d}_{1}\right)$ changes the coke production significantly, while also showing an increase then decrease in benzene production as $\mathbf{d}_{1}$ increases, seen in Figure 11. The coke production increases because as $\mathbf{d}_{1}$ increases, the $\mathbf{A}_{\mathbf{r}}$ increases, leading to enlarging of reaction rate effects on the molar balance, allowing for the DMA reactions to complete quicker along the length of the reactor. Only the pyrolysis reactions take place after the DMA reactions reach equilibrium in the reactor. The benzene production and the methane conversion show similar effects for cases with 
small diameters, increasing as $\mathbf{d}_{1}$ increases. This is because the reactor sizes at low $\mathbf{d}_{1}$ are not large enough for the DMA reactions to reach equilibrium. Once $\mathbf{d}_{1}$ increases enough, the conversion levels off, and the benzene production decreases because benzene flux through $\mathrm{M} 1$ increases with the increase in diameter. These results indicate that $\mathbf{d}_{1}$ should be smaller to mitigate these issues, similarly to the $\mathbf{L}$ effects presented above.
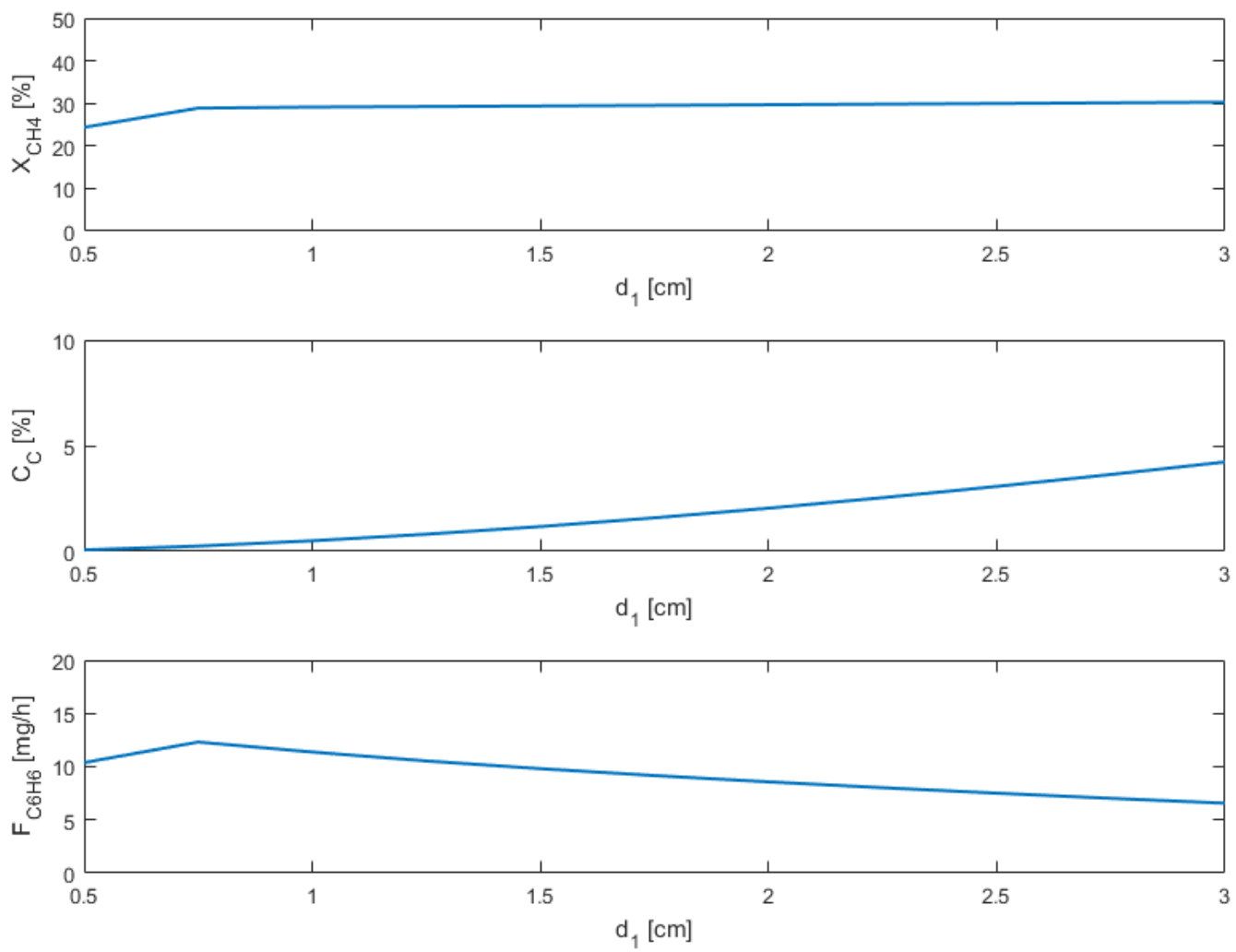

Figure 11. Sensitivity studies of $\mathbf{d}_{\mathbf{1}}$ for model performance criteria: $\mathbf{X}_{\mathbf{C H} 4}$ (top), $\mathbf{C}_{\mathbf{c}}$ (middle), $\mathbf{F}_{\mathbf{c} 6 \mathrm{H} 6}$ (bottom).

M1 permeance $\left(\mathbf{Q}_{1}\right)$ affects the methane conversion the most when compared to other parameters, as depicted in Figure 12, as expected, because the more hydrogen flows out of the reaction zone, the more the equilibrium shifts toward the products. However, too high of a permeance allows for benzene permeation out of the 
reaction zone. The study shows that the best permeance value is difficult to determine using sensitivity studies, especially if other variables are changing, so the use of objective function is necessary.
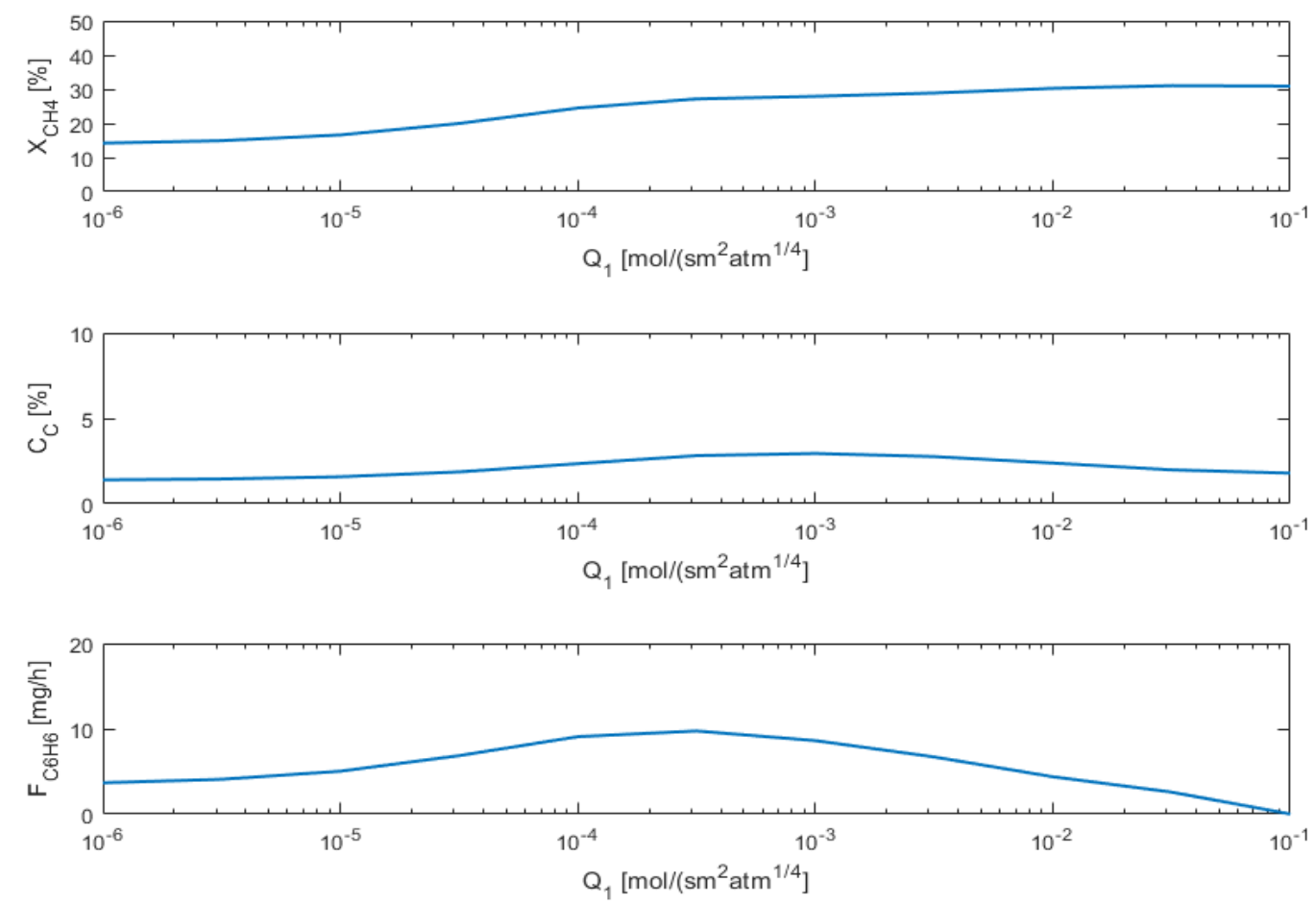

Figure 12. Sensitivity studies of $\mathbf{Q}_{1}$ for model performance criteria: $\mathbf{X}_{\mathbf{C H}_{4}}$ (top), $\mathbf{C}_{c}$ (middle), $\mathbf{F}_{\mathbf{c} 6 \mathrm{H} 6}$ (bottom).

Varying the selectivity to other species for $\mathrm{M} 1\left(\boldsymbol{\alpha}_{\mathrm{i}, 1}\right)$ mainly affects the benzene production, shown below in Figure 13, as expected. Low selectivity allows much of the benzene to permeate through $\mathrm{M} 1$, while higher selectivity allows more benzene to stay in the reaction zone. This also affects the coke production as the reactants that form the products from coke also permeate through M1 at lower selectivity, decreasing the rate of coking. The effects on benzene production are still much greater than the effects on coke production. This result indicates that selectivity will need to be high enough for optimal results. 

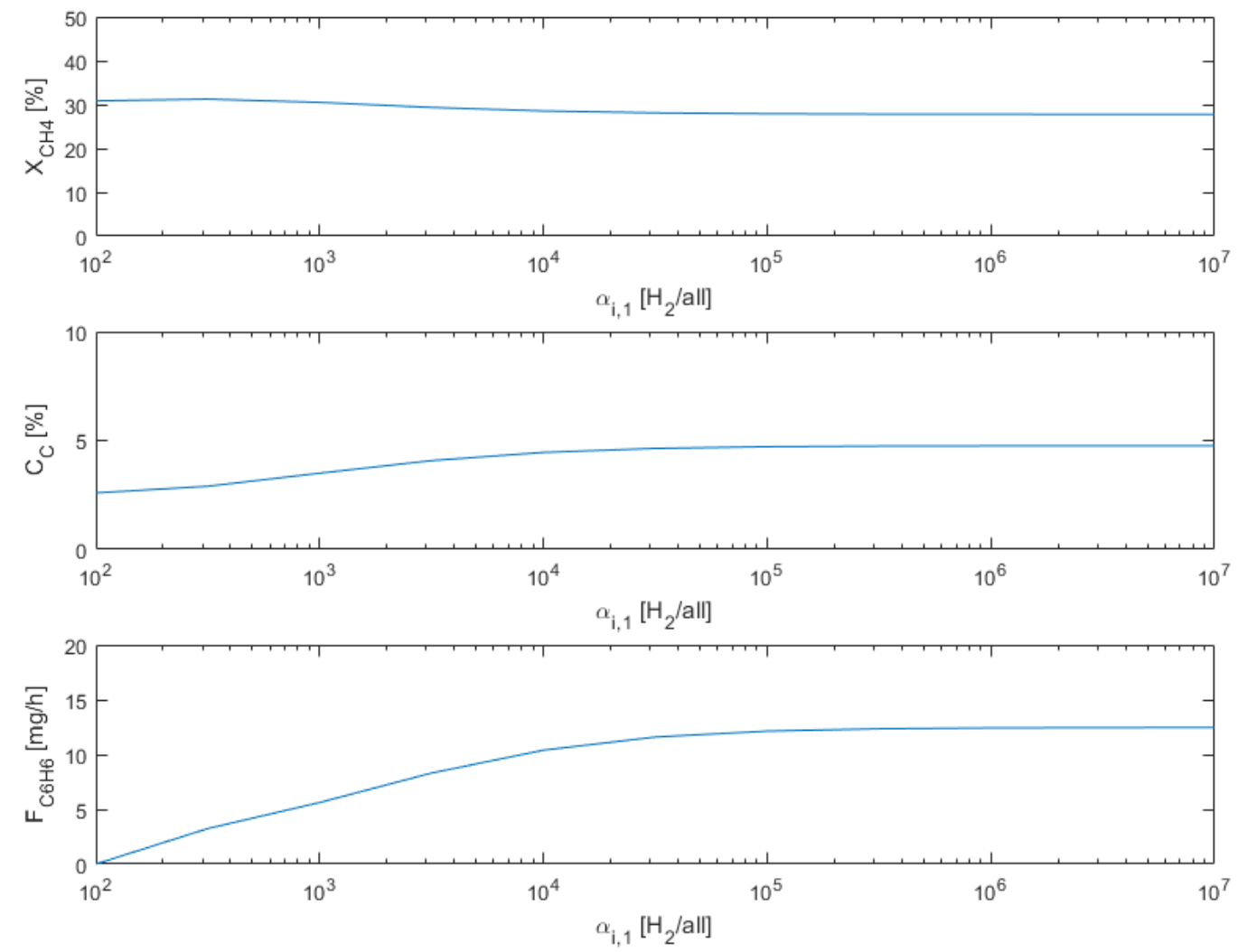

Figure 13. Sensitivity studies of $\boldsymbol{\alpha}_{\mathrm{i}, 1}$ for model performance criteria: $\mathbf{X}_{\mathbf{C H} 4}$ (top), $\mathbf{C}_{c}$ (middle), $\mathbf{F}_{\mathbf{c} 6 \mathrm{H} 6}$ (bottom).

Due to their significant effects on the three performance criteria, reactor length as well as diameter, permeance, and selectivity for M1 are chosen for future studies to be able to determine the best multifunctional membrane reactor design.

\subsection{Optimization and Operability Mapping}

Operability mapping studies follow a region of input variables in the AIS in order to determine the best reactor design based on the performance criteria defined for the output variables in the AOS. The best point can then be selected from the output region using the optimization method described above. The ranges of variables for the AIS are decreased here from the base case in order to more finely observe such variable effects. 
First, the performance is assessed when varying the reactor dimensions (reactor length and $\mathrm{M} 1$ diameter), using $\mathbf{Q}_{1}=0.01 \mathrm{~mol} / \mathrm{s} \cdot \mathrm{m}^{2} \cdot$ atm $^{1 / 4}$ and $\boldsymbol{\alpha}_{\mathrm{i}, 1}=1000$, chosen as typical estimates of membrane parameters, as shown in Figure 14. In particular, from points "A" to "B," as the length increases, the coking effects also increase and the benzene production decreases due to pyrolysis and benzene permeation as reported above. From points "B" to "C" the diameter is increased, so more cross-sectional area for the DMA reaction, along with all the other reactions, is present to take place in. Thus, the coking effects dramatically increase with the larger area and benzene is consumed in the process. The best design based on the optimization for these cases is determined to be a small reactor $\left(\mathbf{d}_{1}=1.65 \mathrm{~cm}, \mathbf{L}=10\right.$ $\mathrm{cm}$ ) with an $L / D \approx 7$. This $L / D$ is far too small for the plug flow assumption of $L / D>15$ [22], and, therefore, not a realistic solution. Whenever this constraint is applied, a new optimal design is obtained, denoted by the star point in Figure $14\left(d_{1}=1.5 \mathrm{~cm}, L=20\right.$ $\mathrm{cm})$. These results are interesting because they demonstrate the flexibility of the formulated optimization problem and the variability of the optimal result depending on the incorporated process constraints. Thus, this means that the best design based on the objective function in Equation 49 calls for a short reactor with a total volume just large enough to allow for the DMA reactions to reach equilibrium. 

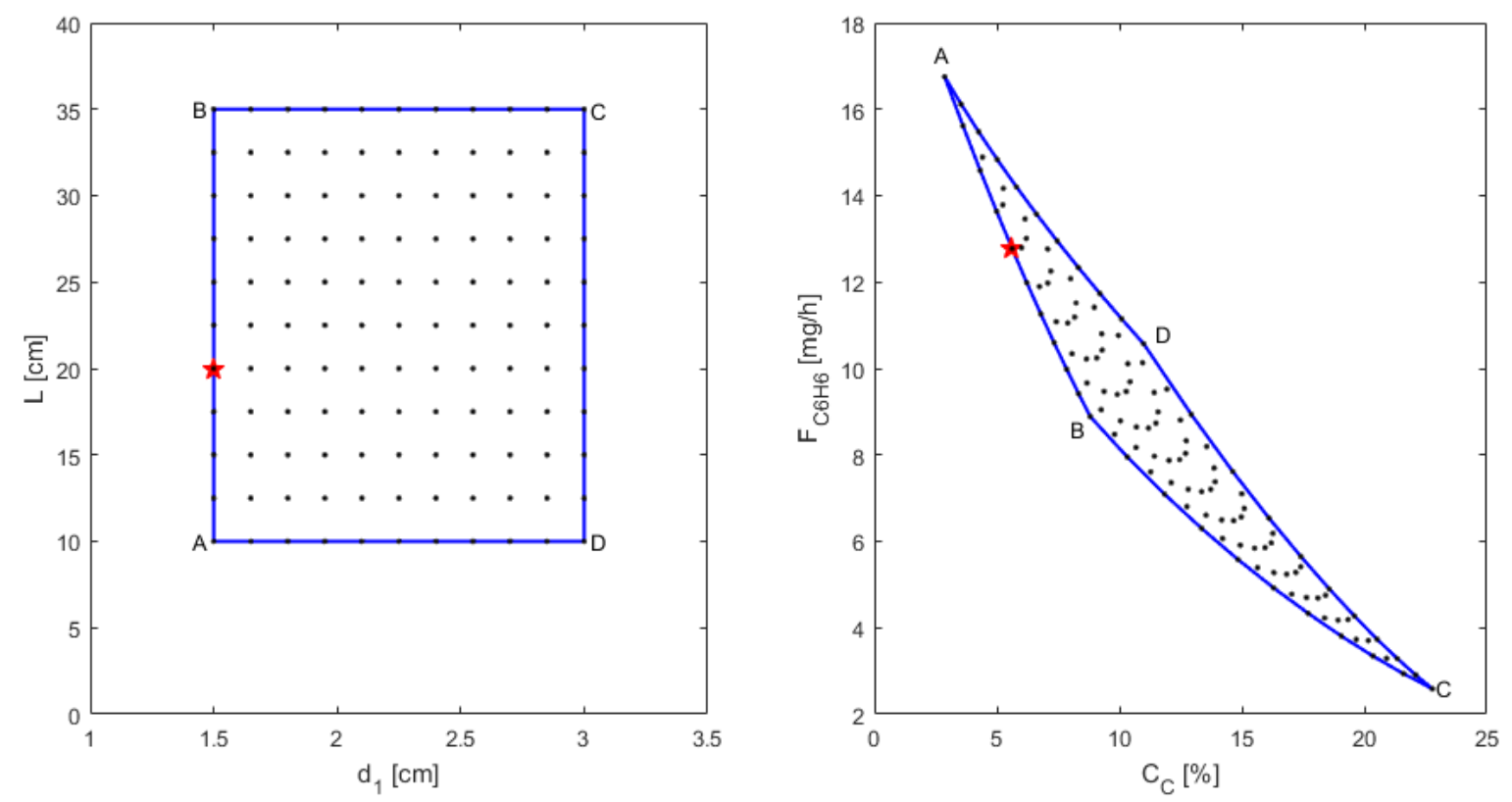

Figure 14. AIS - reactor dimensions (left), AOS - $\mathbf{C}_{c}$ and $\mathbf{F}_{\mathrm{C}_{6 \mathrm{H}} 6}$ (right).

The membrane design for $\mathrm{M} 1$ is assessed next, by varying $\mathrm{Q}_{1}$ and $\mathrm{a}_{\mathrm{i}, 1}$ and using $\mathbf{L}=20 \mathrm{~cm}$ and $\mathbf{d}_{\mathbf{1}}=1.5 \mathrm{~cm}$, chosen from the previous study's optimal point, as depicted in Figure 15. In this figure, from points "A" to "B," the membrane selectivity is increased, which leads to a sharp increase in benzene production and a small increase in coking effects. This is due to less benzene leaving the reaction zone, possibly allowing for more benzene and other reaction products to be converted to coke. In segment "B" to "C," the coking effects decrease possibly because more hydrogen is left in the reaction zone due to low permeance, while the benzene production decreases because there is less conversion when permeance is low, again due to more hydrogen in the reaction zone. In the "C" to "D" segment in the AIS, selectivity is decreased, but interestingly, the changes in the AOS are negligible, highlighting that at low permeance, selectivity has little effect on the performance criteria. From point "D" back to "A," it is observed that the benzene production first 
increases sharply, then it decreases while the permeance increases. This makes sense, since at a low selectivity, increasing permeance allows for more hydrogen to pass through the membrane, thus leading to higher conversion; however, eventually the permeance gets large enough for benzene and its reactants to flow through the membrane, thus losing production overall. Hence, there is a sensitive balance at work with the permeance at low selectivity. The optimal design can thus be determined to have a membrane to allow for a mid-range to high permeance with a high selectivity, denoted by the star point $\left(\mathbf{Q}_{1}=5 \times 10^{-4} \mathrm{~mol} / \mathrm{s} \cdot \mathrm{m}^{2} \cdot \mathrm{atm}^{1 / 4}, \boldsymbol{\alpha}_{\mathrm{i}, 1}=2 \times 10^{6}\right)$. As it may be difficult to achieve a very high selectivity in laboratory conditions, it is suggested that the best design has a lower selectivity as an alternative for a mid-range permeance, as the optimal results in this case would change by $<10 \%$, seen at the red circle point $\left(\mathbf{Q}_{1}=5 \times 10^{-4} \mathrm{~mol} / \mathrm{s} \cdot \mathrm{m}^{2} \cdot \mathrm{atm}^{1 / 4}, \boldsymbol{\alpha}_{\mathrm{i}, 1}=10^{3}\right)$. The performed operability mapping thus also allow for determining alternative optimal designs for the membrane reactor system.
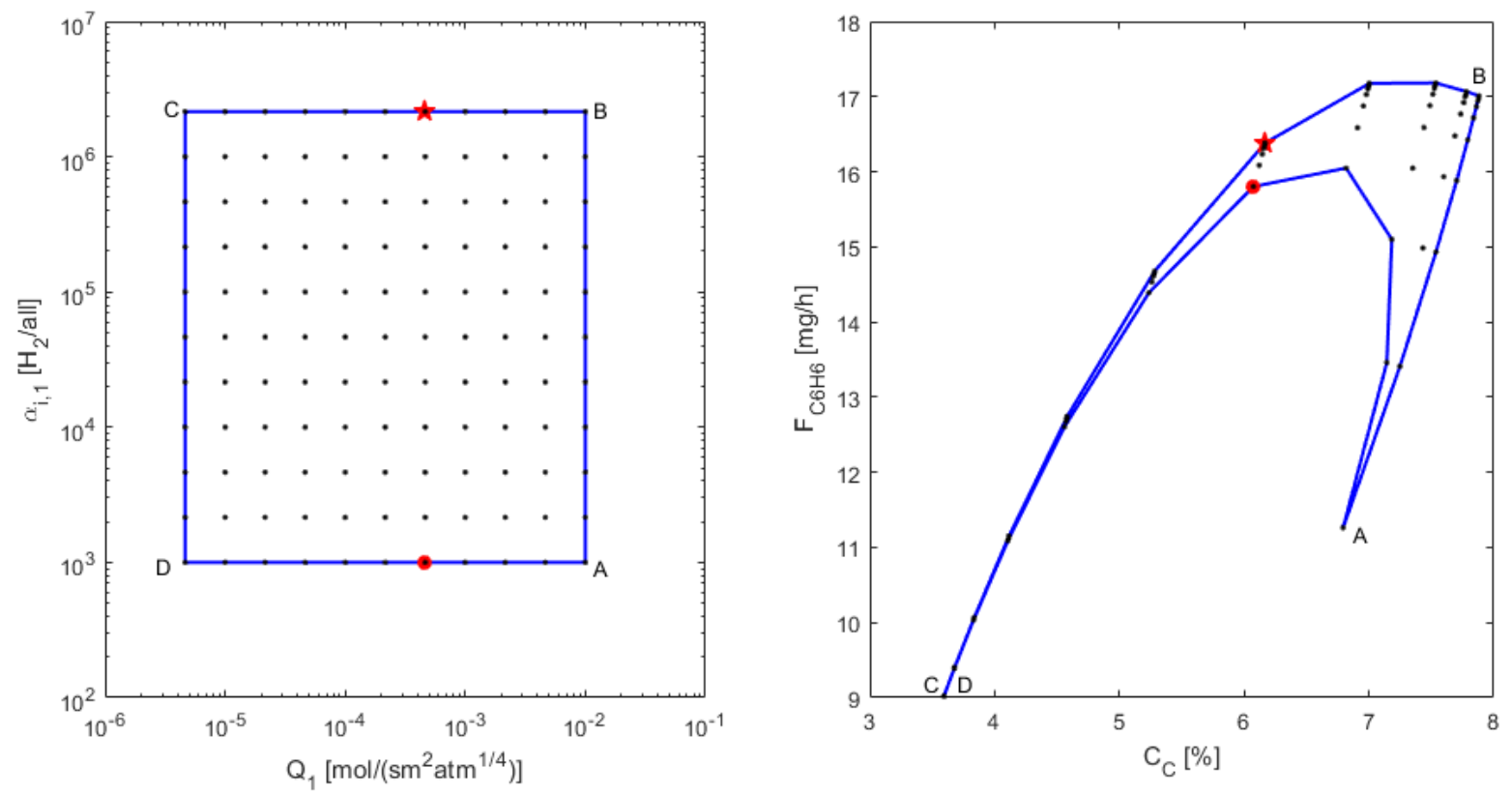

Figure 15. AIS - M1 permeance and selectivity to hydrogen (left), AOS - $\mathbf{C}_{c}$ and $\mathbf{F}_{\mathbf{c} 6 \mathrm{H} 6}$ (right). 
The membrane design for $\mathrm{M} 2$ is then studied to determine if tracking $\mathbf{Q}_{\mathbf{2}}$ and $\mathbf{d}_{\mathbf{2}}$ with constant $\mathbf{A r}_{\mathbf{r}}=1 \mathrm{~cm}^{2}$, determined to be the clearest representation of the oxygen addition effects in the sensitivity studies above, will significantly change the performance criteria, as the criteria changes were not significant in the sensitivity studies when the two inputs were changed separately. The diameter of M1 ( $\left.\mathbf{d}_{1}\right)$ is also increased from $\sim 1.23 \mathrm{~cm}$ to $2.3 \mathrm{~cm}$ accordingly due to a constant $A_{\text {r. }}$ The results are shown in Figure 16. From point "A" to "B," the diameter is increased, so both fluxes for M1 and M2 also increase. This leads to decreasing coke production, but benzene production significantly decreases as well. This is due to higher fluxes through M1 from increased $\mathbf{d}_{1}$. At segment " $B$ " to "C," the permeance of M2 is decreased, allowing lower oxygen flow through the membrane. This increases coking due to less oxygen, but the benzene production increases as well, as seen above in Figure 6 . This is due to high selectivity to OCM products when oxygen flow is high. From point "C" to "D," $d_{2}$ is decreased allowing the coke and benzene production to both increase. This is due to both the above effects of lower flux through both membranes due to diameter reduction and less oxygen flux allowing for lower conversion to OCM products. Finally, from point "D" back to point "A," the permeance increases, decreasing both coke production and benzene production, due to similar reasons stated above. The point "D" is also the optimal design point according to the defined objective function $\left(\mathbf{d}_{1}=1.23 \mathrm{~cm}, \mathbf{d}_{2}=0.5 \mathrm{~cm}, \mathbf{Q}_{2}=2.09 \times 10^{-5} \mathrm{~mol} / \mathrm{s} \mathrm{m}^{2} \cdot\right.$ atm $\left.^{1 / 4}\right)$. These results show that while oxygen addition into the DMA system does help to mitigate coke production, it may also hinder benzene production due to higher reaction selectivity to OCM products, depending on the considered objective function. 

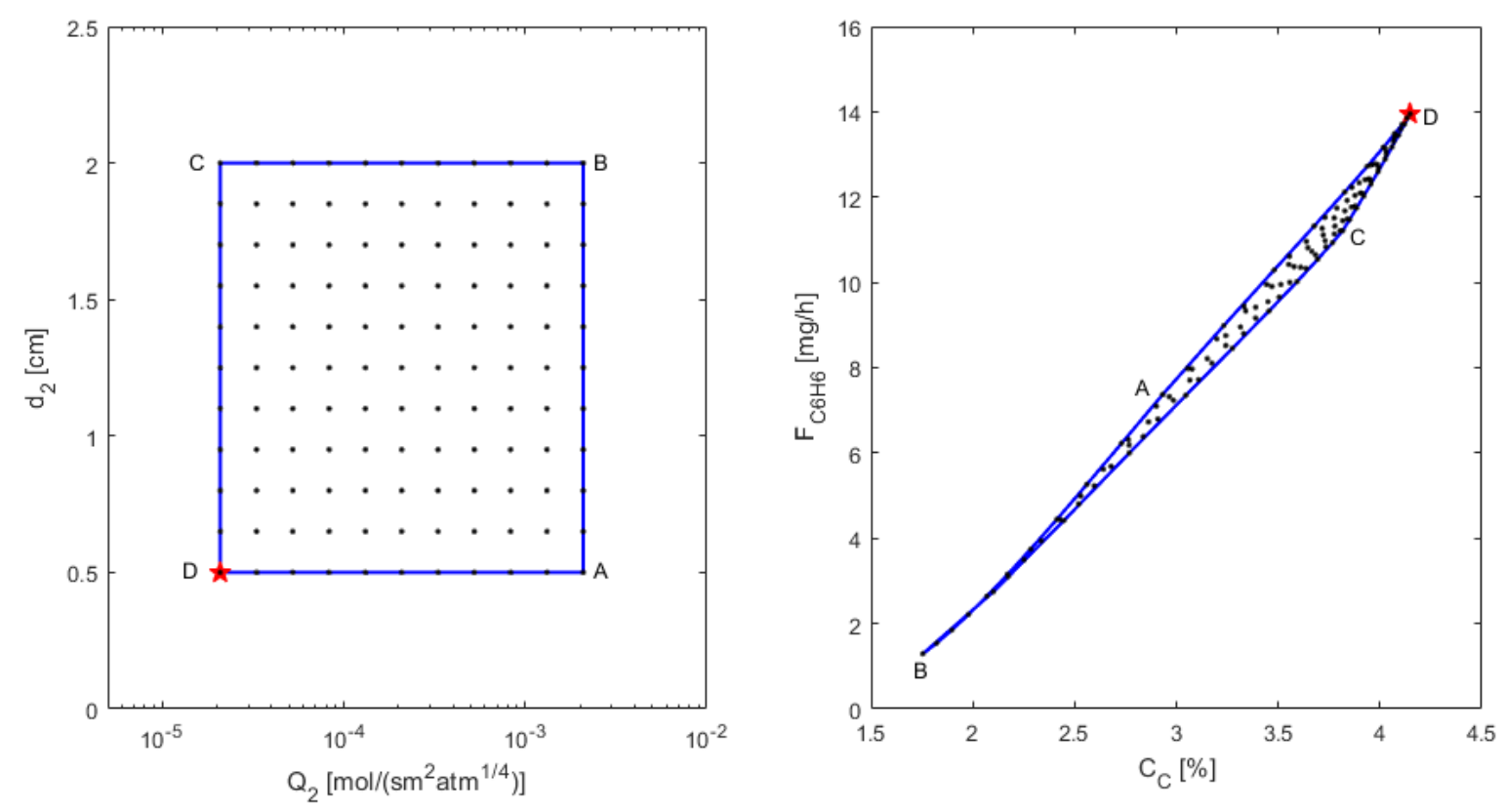

Figure 16. AIS - Permeance and diameter for M2 (left), AOS - $\mathbf{C}_{\mathbf{c}}$ and $\mathbf{F}_{\mathbf{c} 6 \mathrm{H} 6}$ (right).

In the final study completed, four of the above design parameters $\left(\mathbf{L}, \mathbf{d}_{\mathbf{1}}, \mathbf{Q}_{\mathbf{1}}\right.$, $\left.\boldsymbol{\alpha}_{\mathrm{i}, 1}\right)$ are varied, as shown in Figure 17. M2 parameters $\left(\mathbf{d}_{\mathbf{2}}, \mathbf{Q}_{\mathbf{2}}\right)$ were excluded from this study due to their relatively low overall contributions to the performance criteria. Selectivity, $\boldsymbol{\alpha}_{\mathrm{i}, 1}$, is not considered in the figure for graphical purposes and due to the fact that the optimal designs always had the maximum selectivity. Table 5 shows the optimal designs obtained within the range simulated, as well as the optimal performance criteria for different cases considering higher weights for specific performance criteria. Case 1 uses the objective function $\varphi$ shown in Equation 49, while Cases 2-4 use 100 times weight toward benzene production, methane conversion, and coke production, respectively. The considered ranges are similar to the ones used in the mapping studies with two inputs. The maximum/minimum range values assumed for some of the inputs are also presented in Table 5 to account for membrane properties that would be more feasible in a laboratory setting. As noted 
before, high permeance and high selectivity for M1 allows for the most hydrogen to leave the system, allowing for increased conversion of methane, while also allowing for the desired benzene to stay in the reaction zone. A small reactor is shown to give the lowest coke formation, but the reactor must be large enough to convert the feed and still be considered a plug flow reactor. Given these considerations, zone "a" in Figure 17 shows the optimal region: high permeance and selectivity with small reactor dimensions. This zone contains the best designs according to the objective function for Case 1 and Case 2, denoted by the large star and the circle, respectively. Cases 1 and 2 have very similar results, showing that high benzene production coincides with low coke production and high conversion. The zone "b" shows the region with small reactor dimensions with low permeance, not allowing for the equilibrium of the DMA reactions to be shifted toward the products through hydrogen removal. The optimal point for Case 4 is contained in zone "b," denoted by the diamond point, and since permeance is low, the reactor acts as a tubular reactor with no M1, only M2, such as in the base case simulations above. The criteria are at very low values due to low reaction volume, so minimal coking also coincides with little feed reacting. Region "c" is where larger reactor dimensions are used with high permeance, highlighted by the large amount of coke production that occurs. The best design for Case 3 is in this zone, denoted by the square point, showing that maximal conversion can also lead to high coke production and low benzene production. This is due to the large reactor dimensions allowing for pyrolysis and benzene permeation as explained above. The optimization studies performed thus demonstrate that this multifunctional membrane reactor for a DMA system should have a small volume to inhibit the coking effects and a high permeance through $\mathrm{M} 1$ for conversion enhancement. 

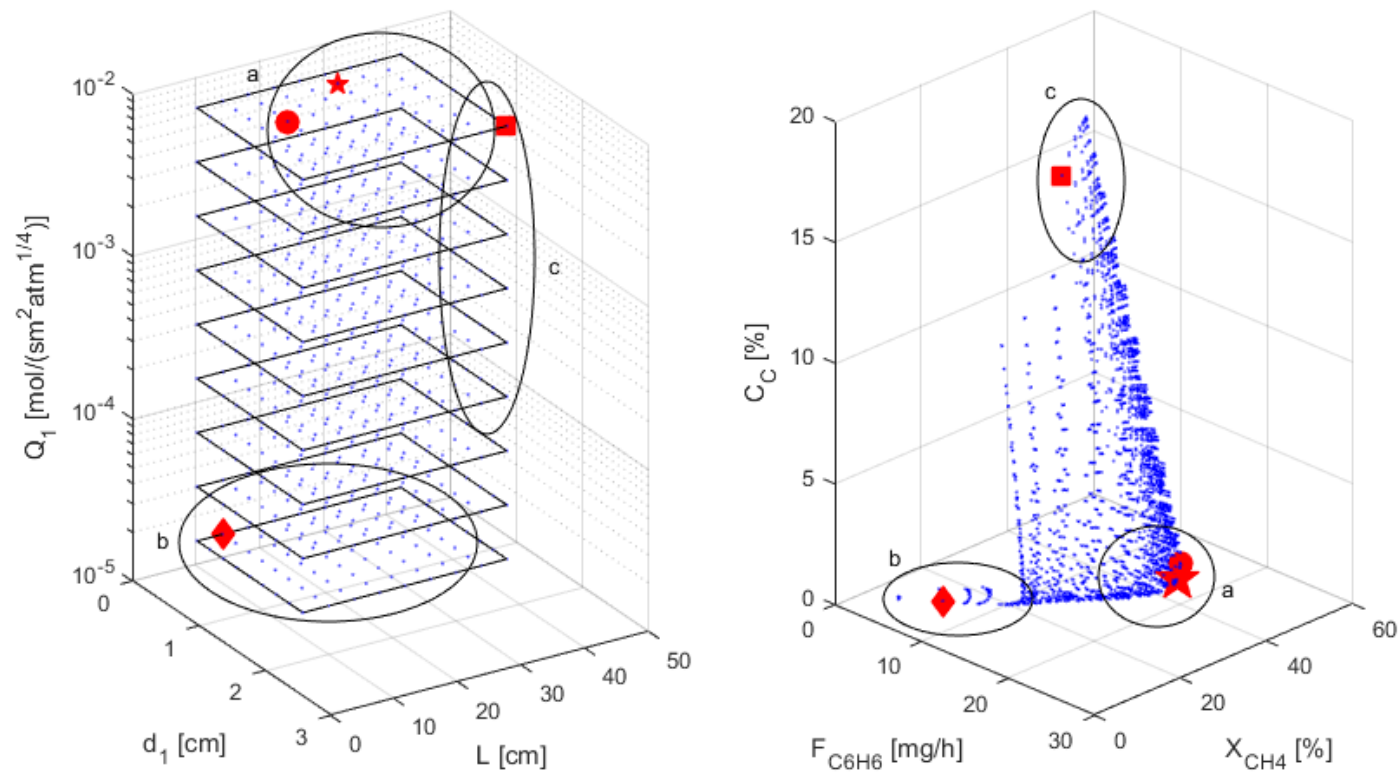

Figure 17. AIS - reactor dimensions and M1 permeance (left), AOS - performance criteria (right).

Table 5. Optimal reactor designs and outputs with modified objective functions: Case 1 has equally weighted criteria, as seen in $\boldsymbol{\varphi}$; Case 2 has 100 times weight on $\mathbf{F}_{\mathrm{C} 6 \mathrm{H} 6}$; Case 3 has 100 times weight on $\mathbf{X}_{\mathbf{c H} 4}$; Case 4 has 100 times weight on $\mathbf{C}$.

\begin{tabular}{|c|c|c|c|c|}
\hline Parameter/Criteria (unit) & Case 1 & Case 2 & Case 3 & Case 4 \\
\hline $\mathbf{L}(\mathrm{cm})$ & 25 & 13 & 37 & 9 \\
\hline $\mathbf{d}_{1}(\mathrm{~cm})$ & 0.7 & 1.1 & 2.1 & 0.5 \\
\hline$Q_{1}\left(\mathrm{~mol} / \mathrm{s} \mathrm{m}^{2} \cdot \mathrm{atm}^{1 / 4}\right)$ & $0.01 *$ & 0.01 & 0.01 & $2.15 \times 10^{-5 \#}$ \\
\hline $\boldsymbol{\alpha}_{\mathbf{i}, \mathbf{1}}\left(\mathrm{H}_{2} / \mathrm{all}\right)$ & $4.64 \times 10^{5}$ * & $4.64 \times 10^{5}$ & 1,000 \# & $4.64 \times 10^{5}$ \\
\hline$F_{\mathrm{C} 6 \mathrm{H} 6}(\mathrm{mg} / \mathrm{h})$ & 20.66 & 20.88 & 5.22 & 5.97 \\
\hline $\mathrm{X}_{\mathrm{CH} 4}(\%)$ & 37.82 & 38.18 & 42.17 & 13.06 \\
\hline $\mathbf{C}_{\mathrm{c}}(\%)$ & 1.30 & 1.99 & 15.32 & 0.064 \\
\hline
\end{tabular}

${ }^{* / \#}$ Maximum/minimum value in simulated range considered

\section{Conclusions}

A detailed and comprehensive multifunctional membrane reactor model was developed for direct methane aromatization (DMA) that accounts for both oxidative and non-oxidative mechanisms and for coke production. A reaction model was formulated using non-oxidative DMA, oxidative coupling of methane, and aromatics-tosoot pyrolysis reaction mechanisms. This reaction model was then further developed by adding a multifunctional membrane model that allowed for oxygen to permeate 
from an air feed through an oxygen-permeable membrane to the reactor and for hydrogen to permeate through a separate hydrogen-permeable membrane out of the reactor along its length. The hydrogen-permeable membrane is added to drive the equilibrium toward the products for the DMA reaction system. The oxygen-permeable membrane allows for a slow flow of oxygen to enter the DMA system, as previous studies have indicated that the oxygen inhibits coke formation in the reactor. Performance criteria were defined to maximize methane conversion and benzene production, as well as minimize coke production for this DMA system. These performance criteria were used to determine the optimal reactor design given the process conditions by using an objective function. Results showed that the optimal reactor design calls for a reactor short in length $(25 \mathrm{~cm})$, and relatively narrow in diameter $(0.7 \mathrm{~cm})$, to minimize the coking effects on this system. The optimal hydrogen-permeable membrane design was determined to require a high permeance $\left(0.01 \mathrm{~mol} / \mathrm{s} \cdot \mathrm{m}^{2} \cdot \mathrm{atm}^{1 / 4}\right)$ and a high selectivity (greater than $\left.10^{5}\right)$ to hydrogen. If a high selectivity cannot be achieved, a high permeance is best to allow for hydrogen to be removed and shift the equilibrium toward the products. The optimal oxygen-permeable membrane design was also assessed in an independent study and should allow for low flux with a low permeance $\left(2.09 \mathrm{~mol} / \mathrm{s} \cdot \mathrm{m}^{2} . \mathrm{atm}^{1 / 4}\right)$ and should be small in diameter $(0.5 \mathrm{~cm})$ to control the oxygen flux through the membrane, as too much oxygen decreases benzene selectivity. The optimization and operability mapping performed allowed the feasible ranges of expectations for outputs to be determined when further developing this system.

Using this design and model developed, it would be possible to explore how process conditions of feed and sweep molar flow rates, feed compositions accounting 
for co-fed systems, temperature, pressure, and the oxygen-permeable membrane design could affect the DMA reactor system. This will allow for future insights into the process development of more comprehensive and larger-scale DMA systems. This process systems approach has the potential to guide further development of multifunctional membrane reactor models and designs for natural gas utilization systems and other chemical reaction systems.

\section{Recommendations}

\subsection{Process and Design Multivariable Optimization}

The model developed in this thesis can easily be adapted to model behavior of many different outputs while varying many different process and design inputs. Highdimensional analyses may require parallel computing to shorten computational time.

\subsection{Dynamic Reactor Operation}

A steady-state approach was developed in this thesis. Coking is typically observed and studied with continuous operation of a reactor. The reaction model used could be adapted to dynamic operation and could be incorporated into a control interface for implementation of control algorithms. 


\section{References}

1. Anunziata, O., Cussa, J., \& Beltramone, A. (2011). Simultaneous optimization of methane conversion and aromatic yields by catalytic activation with ethane over $\mathrm{Zn}$ ZSM-11 zeolite: The influence of the Zn-loading factor. Catalysis Today, 171(1), 3642.

2. Cao, Z., Jiang, H., Luo, H., \& Baumann, S., Meulenberg, W., Assmann, J., Mleczko, L., Liu, Y., Caro, J. (2013). Natural gas to fuels and chemicals: Improved methane aromatization in an oxygen-permeable membrane reactor. Angew. Chem., 125, 14039-14042.

3. Carrasco, J. C., \& Lima, F. V. (2015). Nonlinear operability of a membrane reactor for direct methane aromatization. In proceedings of the 2015 IFAC ADCHEM Symposium, June 2015.

4. Carrasco, J. C., \& Lima, F. V. (2016). An optimization-based operability framework for process design and intensification of modular natural gas utilization systems. Accepted in Computers and Chemical Engineering.

5. Carrasco, J. C., \& Lima, F. V. (2017). Novel operability-based approach for process design and intensification: Application to a membrane reactor for direct methane aromatization. AlChE Journal, 63(3), 975-983.

6. Choudhary, V., Kinage, A., \& Choudhary, T. (1997). Low-temperature nonoxidative activation of methane over H-galloaluminosilicate (MFI) Zeolite. Science, 275(5304), 1286-1288.

7. Cook, B., Mousko, D., Hoelderich, W., \& Zennaro, R. (2009). Conversion of methane to aromatics over Mo2C/ZSM-5 catalyst in different reactor types. Applied Catalysis A: General, 365(1), 34-41.

8. Fuentes-Cano, D., Gómez-Barea, A., Nilsson, S., \& Ollero, P. (2016). Kinetic modeling of tar and light hydrocarbons during the thermal conversion of biomass. Energy \& Fuels, 30(1), 377-385.

9. Gao, K., Yang, J., Seidel-Morgenstern, A., \& Hamel, C. (2016). Methane dehydroaromatization: Potential of a Mo/MCM-22 catalyst and hydrogene-Selective Membranes. Chem. Ing. Tech., 88(1-2), 168-176.

10. Iliuta, M., Grandjean, B., \& Larachi, F. (2003a). Methane nonoxidative aromatization over Ru-Mo/HZSM-5 at temperatures up to $973 \mathrm{~K}$ in a palladium-silver/stainless steel membrane reactor. Ind. Eng. Chem. Res., 42, 323-330.

11. Iliuta, M., Iliuta, I., Grandjean, B., \& Larachi, F. (2003b). Kinetics of methane nonoxidative aromatization over Ru-Mo/ HZSM-5 catalyst. Ind. Eng. Chem. Res., 42, 3203-3209.

12. Ismagliov, Z., Matus, E., \& Tsikoza, L. (2008). Direct conversion of methane on Mo/ZSM-5 catalysts to produce benzene and hydrogen: Achievements and perspectives. Energy Environmental Science, 1, 526-541. 
13. Ismagliov, Z., Matus, E., Kerzhentsev, M., Ismagliov, I., Dosumov, K., \& Mustafin, A. (2011). Methane conversion to valuable chemicals over nanostructured Mo/ZSM5 catalysts. Petroleum Chemistry, 51(3), 174-186.

14. Kosinov, N., Coumans, F., Uslamin, E., Kapteijn, F., \& Hensen, E. (2016). Selective coke combustion by oxygen pulsing during Mo/ZSM-5-catalyzed methane dehydroaromatization. Angew. Chem. Int. Ed., 55, 15086-15090.

15. Li, L., Borry, R., \& Iglesia, E. (2001). Reaction-transport simulations of non-oxidative methane conversion with continuous hydrogen removal - homogeneousheterogeneous reaction pathways. Chemical Engineering Science, 56, 1869-1881.

16. Li, L., Borry, R., \& Iglesia, E. (2002). Design and optimization of catalysts and membrane reactors for the non-oxidative conversion of methane. Chemical Engineering Science, 57, 4595-4604.

17. Liu, S., Wang, L., Ohnishi, R., \& Ichikawa, M. (1999). Bifunctional catalysis of Mo/HZSM-5 in the dehydroaromatization of methane to benzene and naphthalene XAFS/TG/DTA/MASS/FTIR Characterization and Supporting Effects. Journal of Catalysis, 181(2), 175-188.

18. Liu, S., Ohnishi, R., \& Ichikawa, M. (2003). Promotional role of water added to methane feed on catalytic performance in the methane dehydroaromatization reaction on Mo/HZSM-5 catalyst. Journal of Catalysis, 220(1), 57-65.

19. Lunsford, J. H. (2000). Catalytic conversion of methane to more useful chemicals and fuels: a challenge for the 21st century. Catalysis Today, 63(2-4), 165-174.

20. Mancini, N., \& Mitsos, A. (2011). Ion transport membrane reactors for oxycombustion - Part I: intermediate-fidelity modeling. Energy, 36(8), 4701-4720.

21. Natesakhawat, S., Means, N. C., Howard, B. H., Smith, M., Abdelsayed, V., Baltrus, J., Cheng, Y., Lekse, J., Link, D., \& Morreale, B. (2015). Improved benzene production from methane dehydroaromatization over Mo/HZSM-5 catalysts via hydrogen-permselective palladium membrane reactors. Catal. Sci. Technol., 5, 5023-5036.

22. Paidoussis, M. P. (1998). Fluid-structure interactions: Slender Structures and Axial Flow, Volume 1. San Diego, California: Academic Press. 240.

23. Qiu, P., Lunsford, J., \& Rosynek, M. (1997). Steady-state conversion of methane to aromatics in high yields using an integrated recycle reaction system. Catalysis Letters, 48(1), 11-15.

24. Rival, O., Grandjean, B., Guy, C., Sayari, A., \& Larachi, F. (2001). Oxygen-free methane aromatization in a catalytic membrane reactor. Ind. Eng. Chem. Res., 40, 2212-2219.

25. Skutil, K., \& Taniewski, M. (2006). Some technological aspects of methane aromatization (direct and via oxidative coupling). Fuel processing technology, 87(6), 511-521. 
26. Stansch, Z., Mleczko, L., \& Baerns, M. (1997). Comprehensive kinetics of oxidative coupling of methane over the La2O3/CaO Catalyst. Industrial \& Engineering Chemistry Research, 36(7), 2568-2579.

27. Tempelman, C. H., \& Hensen, E. J. (2015a). On the deactivation of Mo/HZSM-5 in the methane dehydroaromatization reaction. Applied Catalysis B: Environmental, 176-177, 731-739.

28. Tempelman, C. H., Hensen, E. J., \& Zhu, X. (2015b). Activation of Mo/HZSM-5 for methane aromatization. Chinese Journal of Catalysis, 36, 829-837.

29. Tessonnier, J., Louis, B., Rigolet, S., Ledoux, M., \& Pham-Huu, C. (2008). Methane dehydro-aromatization on Mo/ZSM-5: About the hidden role of Brønsted acid sites. Applied Catalysis A: General, 336, 79-88.

30. U.S. EIA. (2017a, February). Where our natural gas comes from. Retrieved from https://www.eia.gov/energyexplained/index.cfm?page=natural_gas_where

31. U.S. EIA. Independent Statistics and Analysis. (2017b, February). Retrieved from https://www.eia.gov/outlooks/steo/report/natgas.cfm

32. Wang, L., Tao, L., Xie, M., \& Xu, G. (1993). Dehydrogenation and aromatization of methane under non-oxidizing conditions. Catalysis Letters, 21, 35-41.

33. Wang, L., Ohnishi, R., \& Ichikawa, M. (1999). Novel rhenium-based catalysts for dehydrocondensation of methane with $\mathrm{CO} / \mathrm{CO} 2$ towards ethylene and benzene. Catalysis Letters, 62(1), 29-33.

34. Wang, L., Ohnishi, R., \& Ichikawa, M. (2000). Selective dehydroaromatization of methane toward benzene on Re/HZSM-5 catalysts and effects of CO/CO2 Addition. Journal of Catalysis, 190(2), 276-283.

35. Wu, Y., Emdadi, L., Wang, Z., Fan, W., \& Liu, D. (2014). Textural and catalytic properties of Mo loaded hierarchical meso-/microporous lamellar MFI and MWW zeolites for direct methane conversion. Applied Catalysis A: General, 470, 344-354.

36. Wu, Y., Emdadi, L., Oh, S., Sakbodin, M., \& Liu, D. (2015). Spatial distribution and catalytic performance of metal-acid sites in Mo/MFI catalysts with tunable meso/microporous lamellar zeolite structures. Journal of Catalysis, 323, 100-111.

37. Xu, Y., Bao, X., \& Lin, L. (2003). Direct conversion of methane under nonoxidative conditions. Journal of Catalysis, 216(1-2), 386-395.

38. Yaws, C. L. (1999). Chemical Properties Handbook. New York: McGraw-Hill Education.

39. Yuan, S., Li, J., Hao, Z., Feng, Z., Xin, Q., Ying, P., \& Li, C. (1999). The effect of oxygen on the aromatization of methane over the Mo/HZSM-5 catalyst. Catalysis Letters, 63, 73-77.

40. Zeng, J., Xiong, Z., Zhang, H., Lin, G., \& Tsai, K. (1998). Nonoxidative dehydrogenation and aromatization of methane over W/HZSM-5-based catalysts. Catalysis Letters, 53(1), 119-124. 